\title{
REVIEWS \\ Prevalence, Predictors, and Treatment of Impostor Syndrome: a Systematic Review
}

Dena M. Bravata, MD, MS ${ }^{1,2}$ (D), Sharon A. Watts, MA ${ }^{2,3}$, Autumn L. Keefer, PhD', Divya K. Madhusudhan, MPH', Katie T. Taylor, PhD ${ }^{2,3}$, Dani M. Clark, BA ${ }^{2,3}$,

Ross S. Nelson, PsyD ${ }^{2,4}$, Kevin O. Cokley, Ph.D. ${ }^{5}$, and Heather K. Hagg, PhD ${ }^{2}$

${ }^{1}$ Center for Primary Care and Outcomes Research, Stanford University School of Medicine, Stanford, CA, USA; ${ }^{2}$ Crossover Health, San Clemente, CA, USA; ${ }^{3}$ Untold Content, Cincinnati, OH, USA; ${ }^{4}$ Welleo Health, San Francisco, CA, USA; ${ }^{5}$ University of Texas at Austin, Austin, TX, USA.

BACKGROUND: Impostor syndrome is increasingly presented in the media and lay literature as a key behavioral health condition impairing professional performance and contributing to burnout. However, there is no published review of the evidence to guide the diagnosis or treatment of patients presenting with impostor syndrome.

PURPOSE: To evaluate the evidence on the prevalence, predictors, comorbidities, and treatment of impostor syndrome.

DATA SOURCES: Medline, Embase, and PsycINFO (January 1966 to May 2018) and bibliographies of retrieved articles.

STUDY SELECTION: English-language reports of evaluations of the prevalence, predictors, comorbidities, or treatment of impostor syndrome.

DATA EXTRACTION: Two independent investigators extracted data on study variables (e.g., study methodology, treatments provided); participant variables (e.g., demographics, professional setting); diagnostic tools used, outcome variables (e.g., workplace performance, reductions in comorbid conditions); and pre-defined quality variables (e.g., human subjects approval, response rates reported). DATA SYNTHESIS: In total, 62 studies of 14,161 participants met the inclusion criteria (half were published in the past 6 years). Prevalence rates of impostor syndrome varied widely from 9 to $82 \%$ largely depending on the screening tool and cutoff used to assess symptoms and were particularly high among ethnic minority groups. Impostor syndrome was common among both men and women and across a range of age groups (adolescents to late-stage professionals). Impostor syndrome is often comorbid with depression and anxiety and is associated with impaired job performance, job satisfaction, and burnout among various employee populations including clinicians. No published studies evaluated treatments for this condition.

LIMITATIONS: Studies were heterogeneous; publication bias may be present.

CONCLUSIONS: Clinicians and employers should be mindful of the prevalence of impostor syndrome among professional populations and take steps to assess for

Received July 29, 2019

Accepted September 12, 2019

Published online December 17, 2019 impostor feelings and common comorbidities. Future research should include evaluations of treatments to mitigate impostor symptoms and its common comorbidities.

KEY WORDS: impostor syndrome; behavioral health; occupational health.

J Gen Intern Med 35(4):1252-75

DOI: $10.1007 / \mathrm{s} 11606-019-05364-1$

(C) The Author(s) 2019

\section{INTRODUCTION}

Impostor syndrome (also known as impostor phenomenon, fraud syndrome, perceived fraudulence, or impostor experience) describes high-achieving individuals who, despite their objective successes, fail to internalize their accomplishments and have persistent self-doubt and fear of being exposed as a fraud or impostor. ${ }^{1}$ People with impostor syndrome struggle with accurately attributing their performance to their actual competence (i.e., they attribute successes to external factors such as luck or receiving help from others and attribute setbacks as evidence of their professional inadequacy). ${ }^{2}$ Psychologists Clance and Imes first described impostor phenomenon in $1978,{ }^{2}$ and it came to widespread public attention after Clance's 1985 book. ${ }^{3}$ Clance originally identified the syndrome among high-achieving professional women, but more recent research has documented these feelings of inadequacy among men and women, in many professional settings, and among multiple ethnic and racial groups. ${ }^{4,5}$

Impostor syndrome is not a recognized psychiatric disorder: It is not featured in the American Psychiatric Association's Diagnostic and Statistical Manual ${ }^{6}$ nor is it listed as a diagnosis in the International Classification of Diseases, Tenth Revision (ICD10). ${ }^{7}$ Outside the academic literature, impostor syndrome has become widely discussed, especially in the context of achievement in the workplace. Perhaps because it is not an officially recognized clinical diagnosis, despite the large peer review and lay literature, although there has been a qualitative review, ${ }^{8}$ there has never been a published systematic review of the literature on impostor syndrome. Thus, clinicians lack evidence on the prevalence, comorbidities, and best practices for diagnosing and 
treating impostor syndrome. Moreover, its actual effects on professional performance and burnout both among healthcare professionals and others are not known.

The purpose of this study was to critically evaluate the published literature on impostor syndrome - specifically to evaluate the prevalence of impostor syndrome in employed populations and characterize its relationship to workplace performance and burnout, characterize common comorbidities, and determine the most effective treatments for populations suffering from impostor symptoms.

\section{METHODS}

\section{Data Sources and Searches}

We developed search strategies for three databases: Medline, Embase, and PsycINFO for citations dated January 1966 to May 2018. We used search terms such as Imposter Syndrome and Impostor Phenomenon (Appendix). We also reviewed bibliographies of retrieved articles to obtain additional citations.

\section{Study Selection}

We considered peer-reviewed studies eligible for inclusion if they reported data on the prevalence, comorbidities, or treatment of impostor syndrome. We excluded studies that were only reported as dissertations, validations of scales to identify impostor syndrome, described dementia- or delirium-based syndromes, or reported cases of legal fraud, impostor drugs, Munchausen's, or Munchausen's by proxy.

\section{Data Extraction and Quality Assessment}

Two authors independently abstracted five types of data from each of the included studies onto pre-tested data collection forms: study variables (e.g., purpose of the study, study methodology, treatments provided); participant variables (e.g., demographics, professional setting); diagnostic tools used to assess for impostor symptoms, outcome variables (e.g., workplace performance, reductions in comorbid conditions); and pre-defined quality variables (e.g., human subjects approval, response rates reported). We resolved abstraction discrepancies by repeated review and discussion. If two or more studies presented the same data from a single patient population, we included these data only once in our analyses.

\section{Lay Literature Search}

While performing background literature searches using general Internet search engines, we noted an abundance of nonpeer-reviewed literature on impostor syndrome. Thus, we undertook a literature search to assess lay interest in the topic of impostor syndrome. We first used the search engine optimization tool Moz to evaluate the key terms used by authors of Internet articles on impostor syndrome. The term Imposter Syndrome was almost exclusively used ("Imposter Syndrome
Test" was also used), whereas Impostor Phenomenon was never used. We then used the content curation and analysis tool BuzzSumo to evaluate the number of Internet articles indexed with the term "Imposter Syndrome" published between March 28, 2018, to March 28, 2019, and to measure the number of times these articles were shared, liked, or commented upon on social media platforms Facebook, Pinterest, Reddit, and Twitter.

\section{Data Synthesis and Analysis}

Given the heterogeneity of the included studies, we summarized the populations assessed, diagnostic tools used, and reported prevalence, comorbidities, and any treatments provided qualitatively. The datasets generated during data collection and analysis are available from the corresponding author on reasonable request.

\section{Role of Funding Source}

This work was funded by Crossover Health, a provider of employer-sponsored health clinics. The funder had no role in this study's design, conduct, or reporting.

\section{RESULTS}

Our searches identified 284 titles of potentially relevant peerreviewed articles (Fig. 1). After synthesizing the data from multiple reports on the same set of participants, 66 articles describing 62 studies with 14,161 participants met our inclusion criteria (Table 1). ${ }^{9-74}$ ]

\section{Study Characteristics}

Although our searches were for the literature starting in 1966, the included studies were all published between 1990 and 2018 (Fig. 2) - notably, half were published in the past 6 years.

Although most of the studies were conducted in the USA ${ }^{9}$, $10,12,13,15-17,21-32,34-38,42,43,45,49-57,61,62,64,65,67,73$ and Canada, ${ }^{19}, 44,46,66,68$ twenty-one studies evaluated populations in other countries including five in Austria, ${ }^{39}, 58-60,63$ five in Australia/New Zealand, ${ }^{20,} 31,70,71,74$ four in Germany, ${ }^{11,14,47,48,58}$ three in Iran, ${ }^{33,} 40,41$ two in the UK, ${ }^{20,69}$ and one each in Belgium ${ }^{72}$ and Korea. ${ }^{73}$

Nearly all of the included studies were single-arm observational studies (Table 1). Most commonly, the authors identified a population of interest, screened them with a validated impostor syndrome questionnaire and other psychometric assessment tools, then described the prevalence of impostor syndrome and co-occurring psychological issues. Two studies also included semi-structured interviews. ${ }^{37,} 38,44$ One study included an experimental design in which subjects were exposed to successes and failures and asked to report on impostor feelings after these exposures. ${ }^{31}$ The only longitudinal assessment was of college students with impostor syndrome who were followed before and after a midterm examination. ${ }^{25}$ 


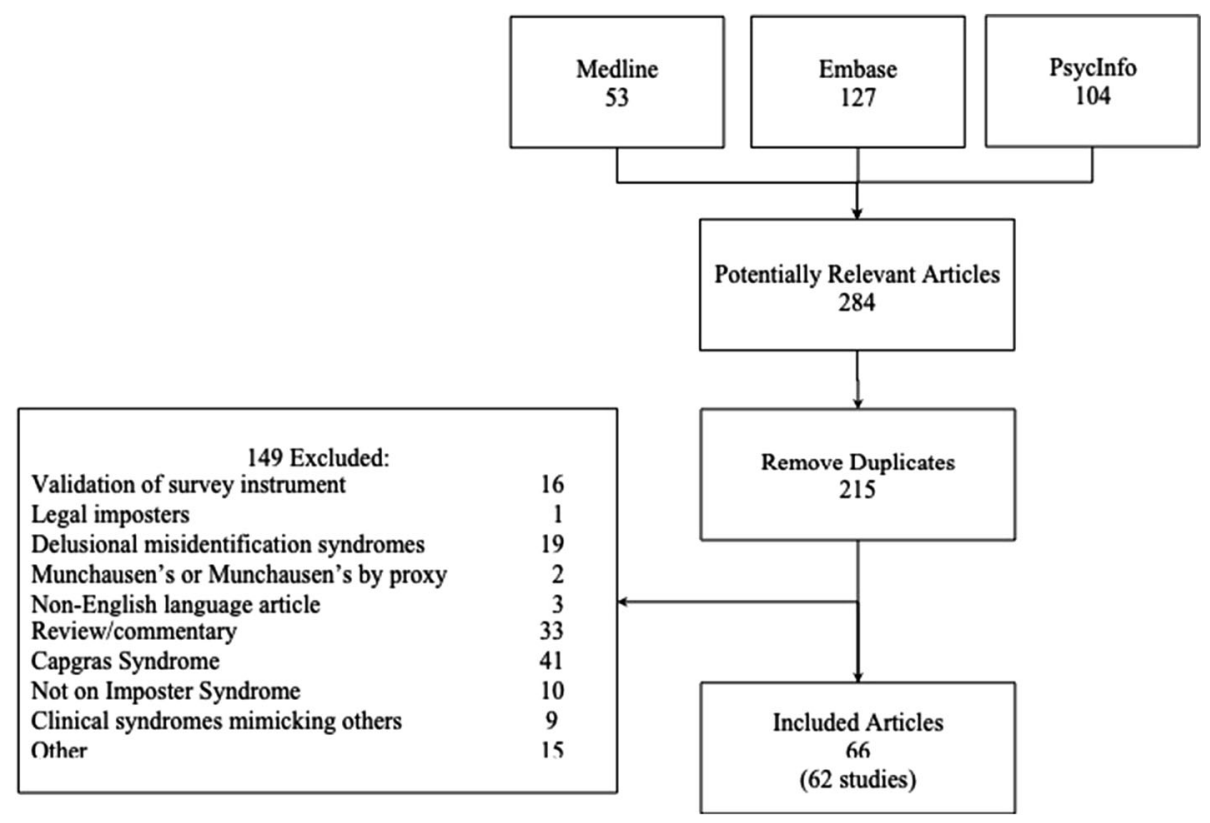

Figure 1 Search results. Presents our search strategies and results.

Notably, there were no randomized trials and only one study presented qualitative information about the clinical management people with impostor syndrome.

Overall, the quality of the included studies was fair: Only 20 studies reporting having Institutional Review Board (IRB)

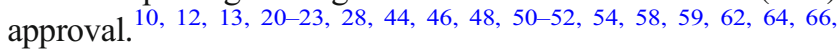
${ }^{73}$ Many studies lacking IRB approval were of student populations - often in the authors' own institutions. Response rates for the populations surveyed ranged from 2.8 to $97.2 \%$ (and many articles did not report response rates) (Table 1).

\section{Participant Characteristics}

The included studies evaluated 14,161 participants, $60 \%$ of whom were women. Among those studies reporting a mean population age, the weighted mean age was 20 years (Fig. 3 ) - not surprising given that 34 of the included studies were of students. However, 17 studies included populations with a mean age of $\geq 30$ years and 5 additional studies were of professional populations but did not report a mean age.]->

Students. Half of the included studies were of student populations: 5 evaluated elementary and high-school students, ${ }^{16}, 19,27,49,6129$ evaluated undergraduates, ${ }^{10,14,20-}$ $25,28,30,31,35,41-43,45,50-52,55-58,63-66,68-70$ and 12 evaluated graduate students. ${ }^{17,} 29,31,33,34,36,39,50,55,65$, 67, 73 Students with impostor syndrome had fears that were significantly related to maintaining their social standing and not wanting to display imperfection to others ${ }^{31}$; however, social support and self-worth were highly negatively associated with impostor symptoms. ${ }^{16}$ Impostor feelings were significantly related to pessimism, perfectionistic traits, and low self-esteem, and although there were no differences in grades between impostors and non-impostors, impostors expected to perform worse and were more anxious about exams. ${ }^{25}$ Interestingly, Ferrari found that students with impostor feelings were significantly less likely to cheat on examinations and to plagiarize written assignments than students without impostor feelings. ${ }^{30}$

Students of Minority Groups. Eleven included articles evaluated impostor syndrome in minority groups. ${ }^{10,12,13,21-}$ 23, 29, 51, 52, 54, 64, 73 They demonstrated that impostor syndrome is common among African American, Asian American, and Latino/a American college students and that impostor feelings are significantly negatively correlated with psychological wellbeing and positively correlated with depression and anxiety. ${ }^{21-}$ 23, 54 Several factors may predispose minority students to increased psychological stress during their educational experiences including lack of adequate financial aid, the need to work to support themselves in school, racial discrimination, enduring negative stereotypes, and being the first in their families to pursue advanced education. ${ }^{21,29}$ Moreover, using MANOVA, one study found that impostor feelings were stronger predictors of mental health than minority status stress. ${ }^{21}$ Austin et al. found that impostor syndrome, depression, and survivor guilt were highly correlated among African American college students. ${ }^{10}$ Bernard et al. found that African American freshmen who reported frequent racial discrimination but low levels of distress from discrimination had higher levels of impostor syndrome than those who reported high levels of distress from racial discrimination. ${ }^{12,13}$ Few non-White individuals have been included in the samples used to standardize the 


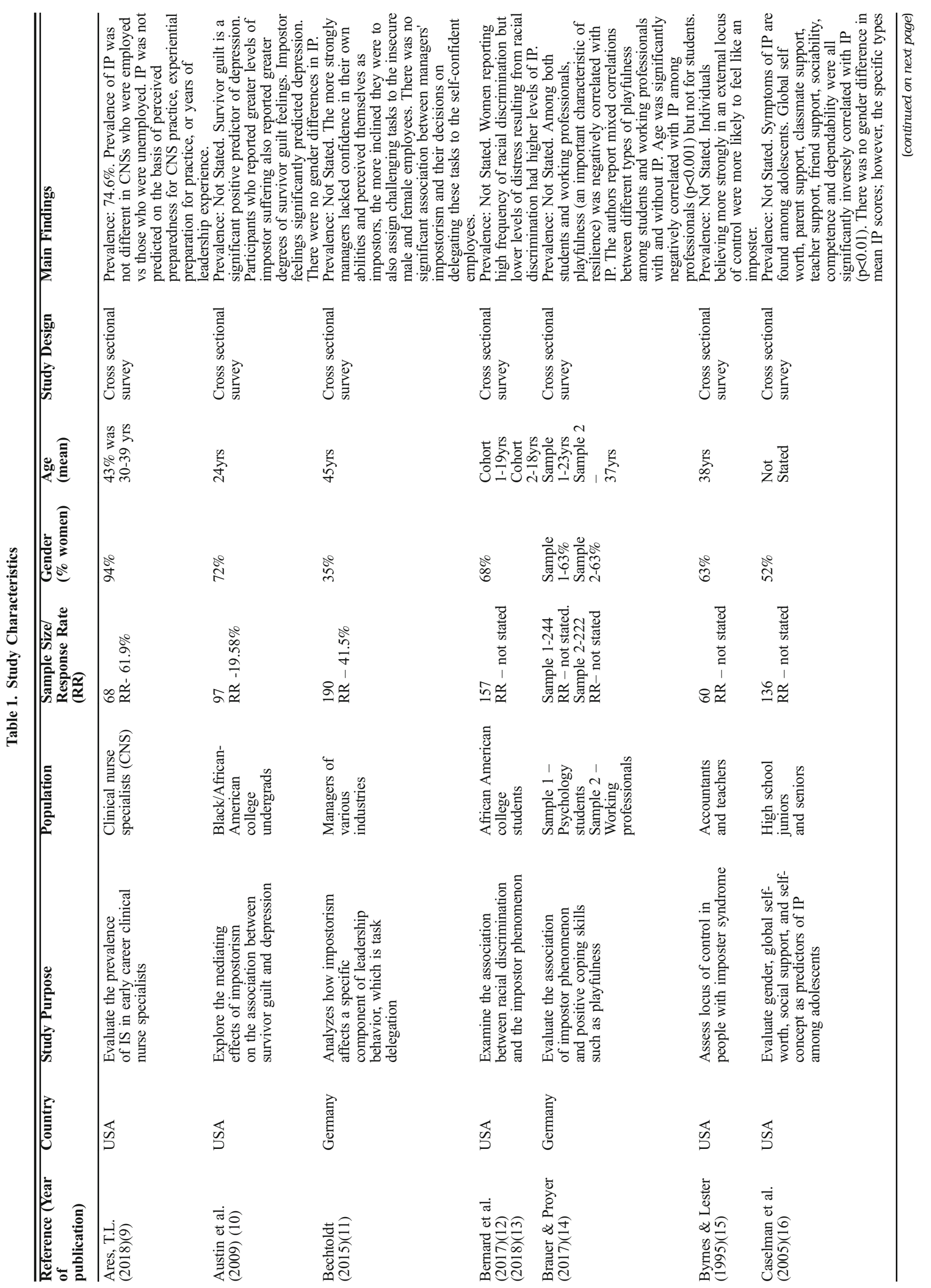




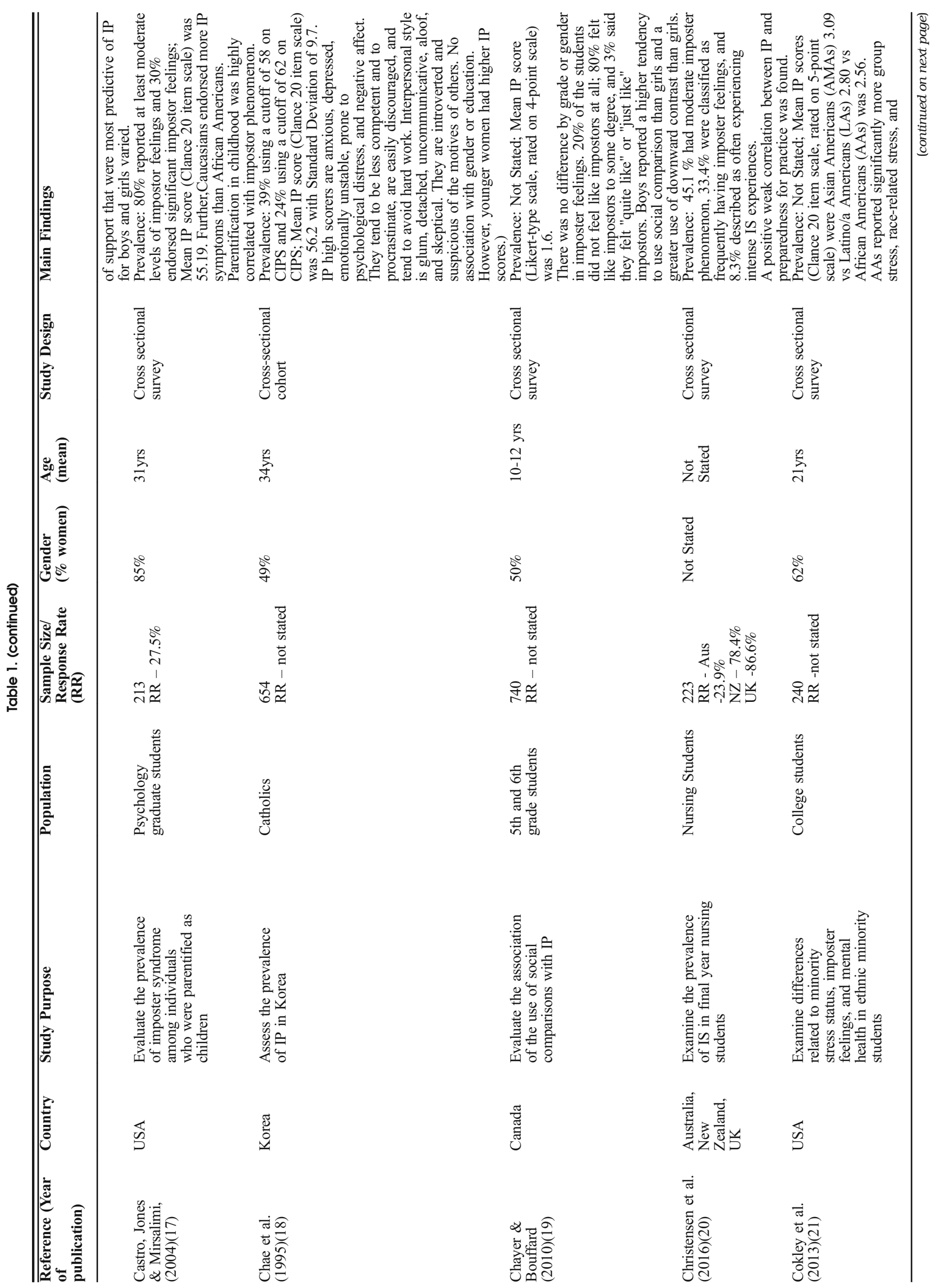




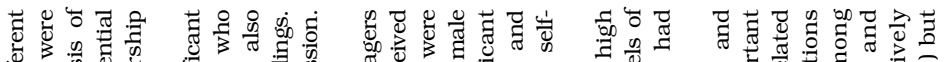

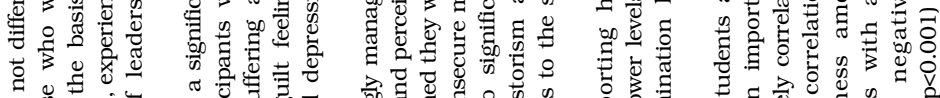

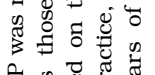

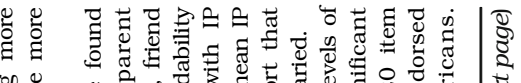

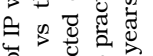

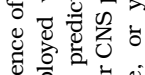

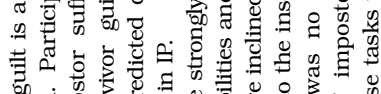

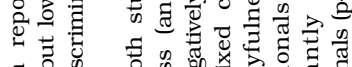

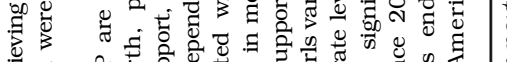

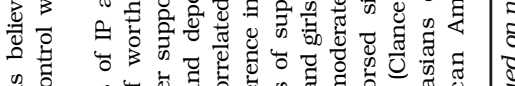

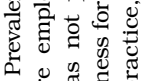

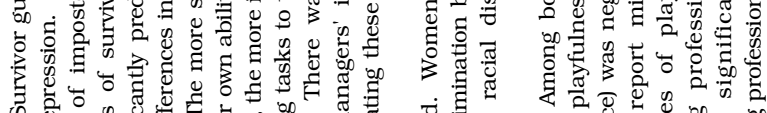

蛋

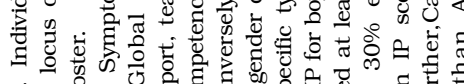

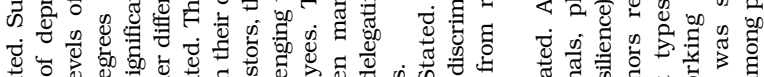

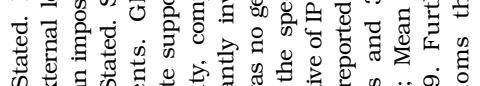

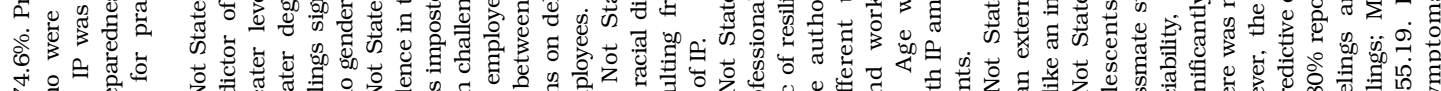

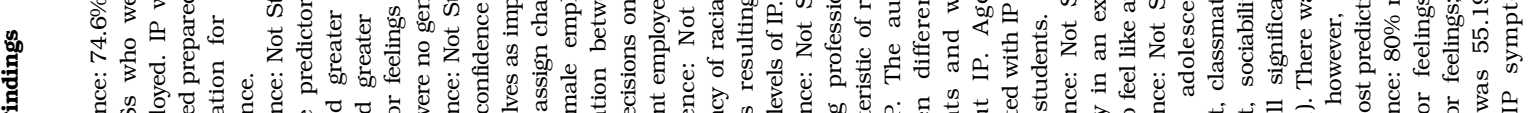

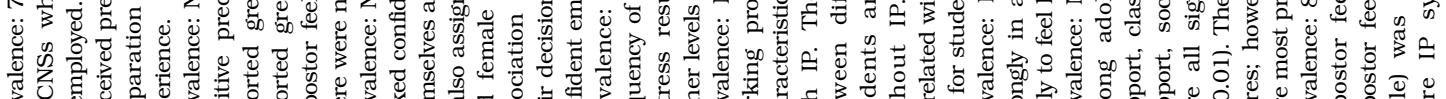

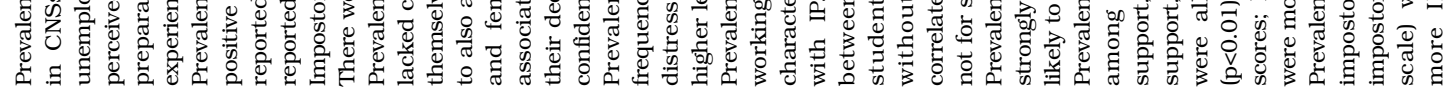

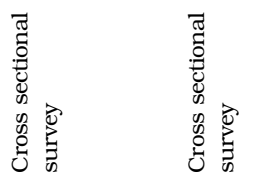

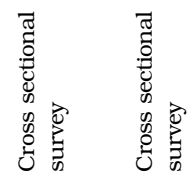

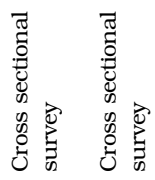

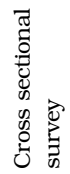

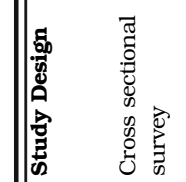

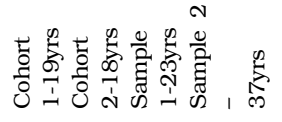

高

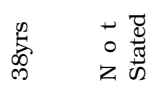

$\underset{\infty}{5}$

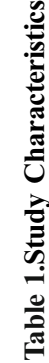

ลิ

ฌั

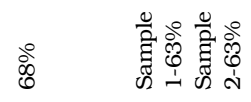

ชั่ ัิे

$\stackrel{\circ}{\infty}$

这

等

के

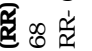

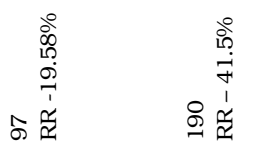

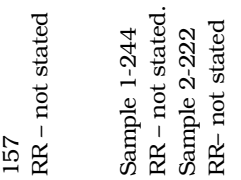

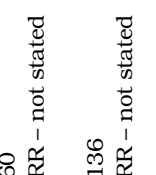

官

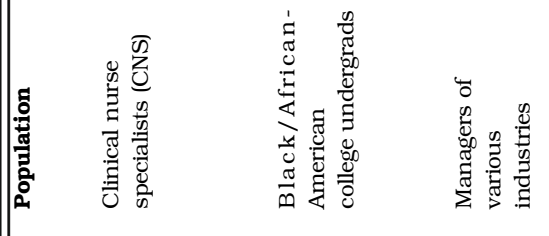

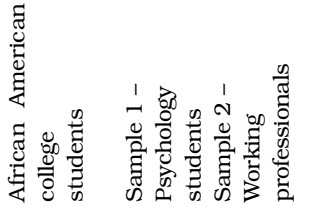

वख्य

군

(

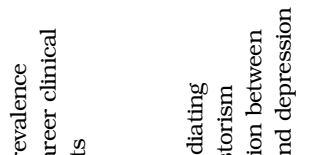

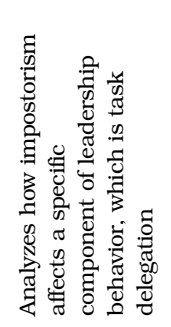

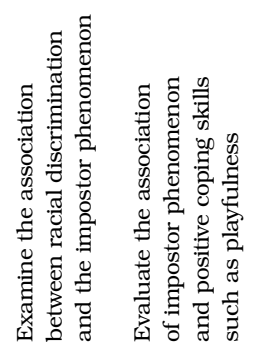

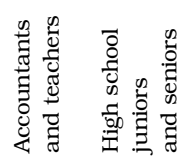

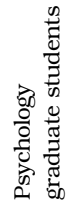

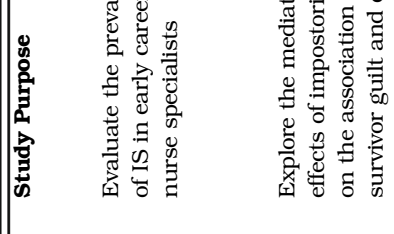

窎

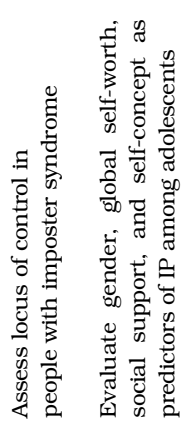

m

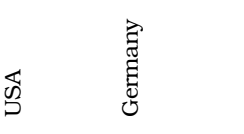

告 告

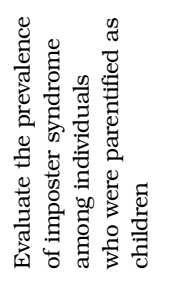

|

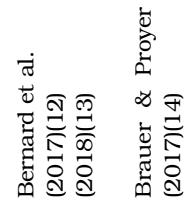

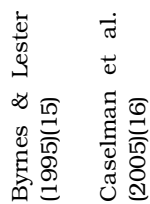

峁

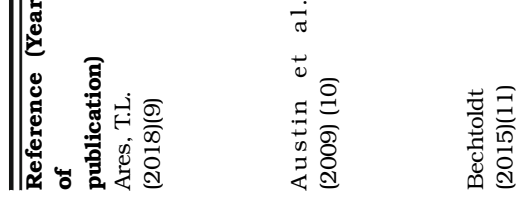

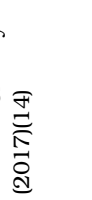




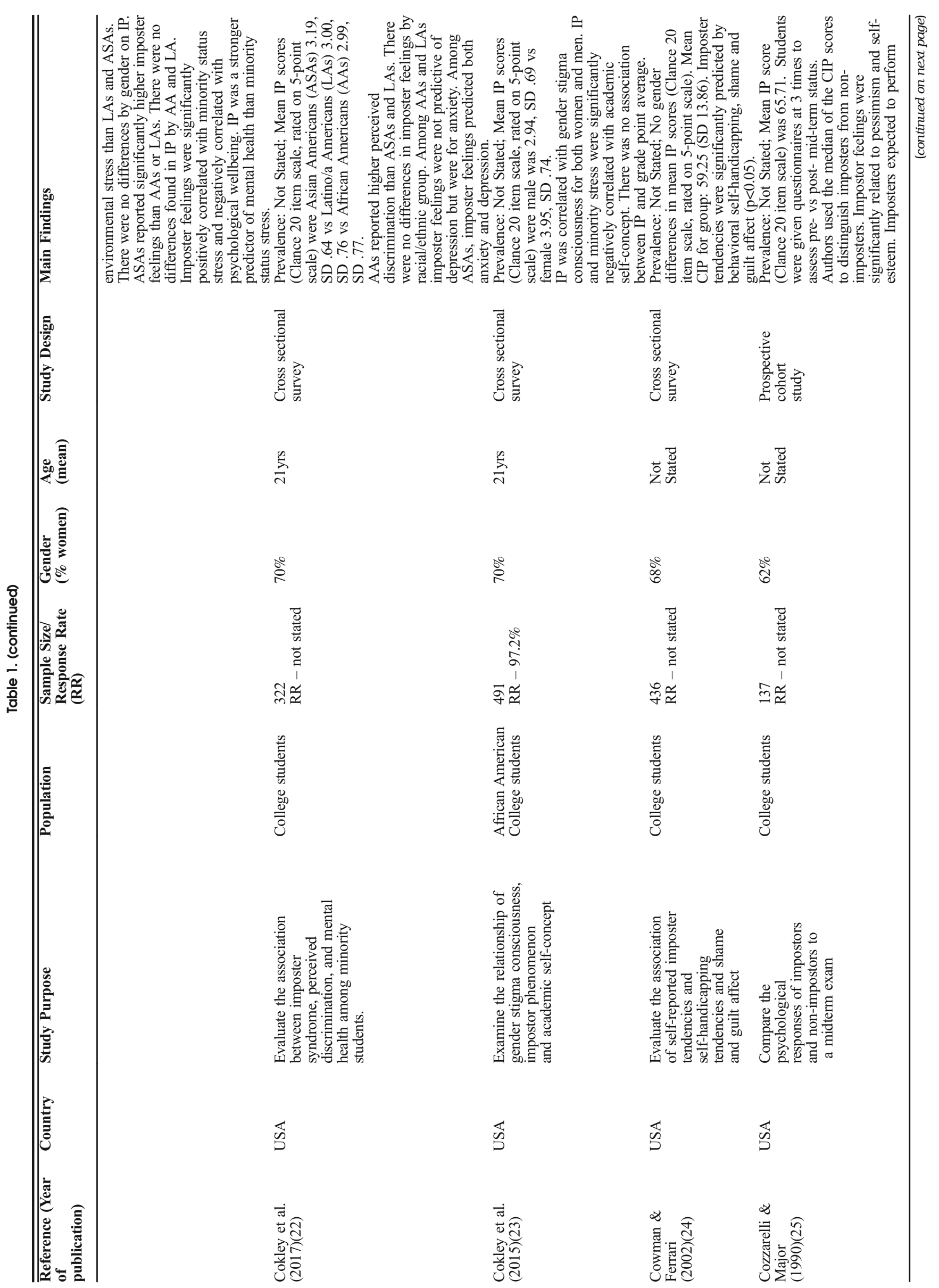




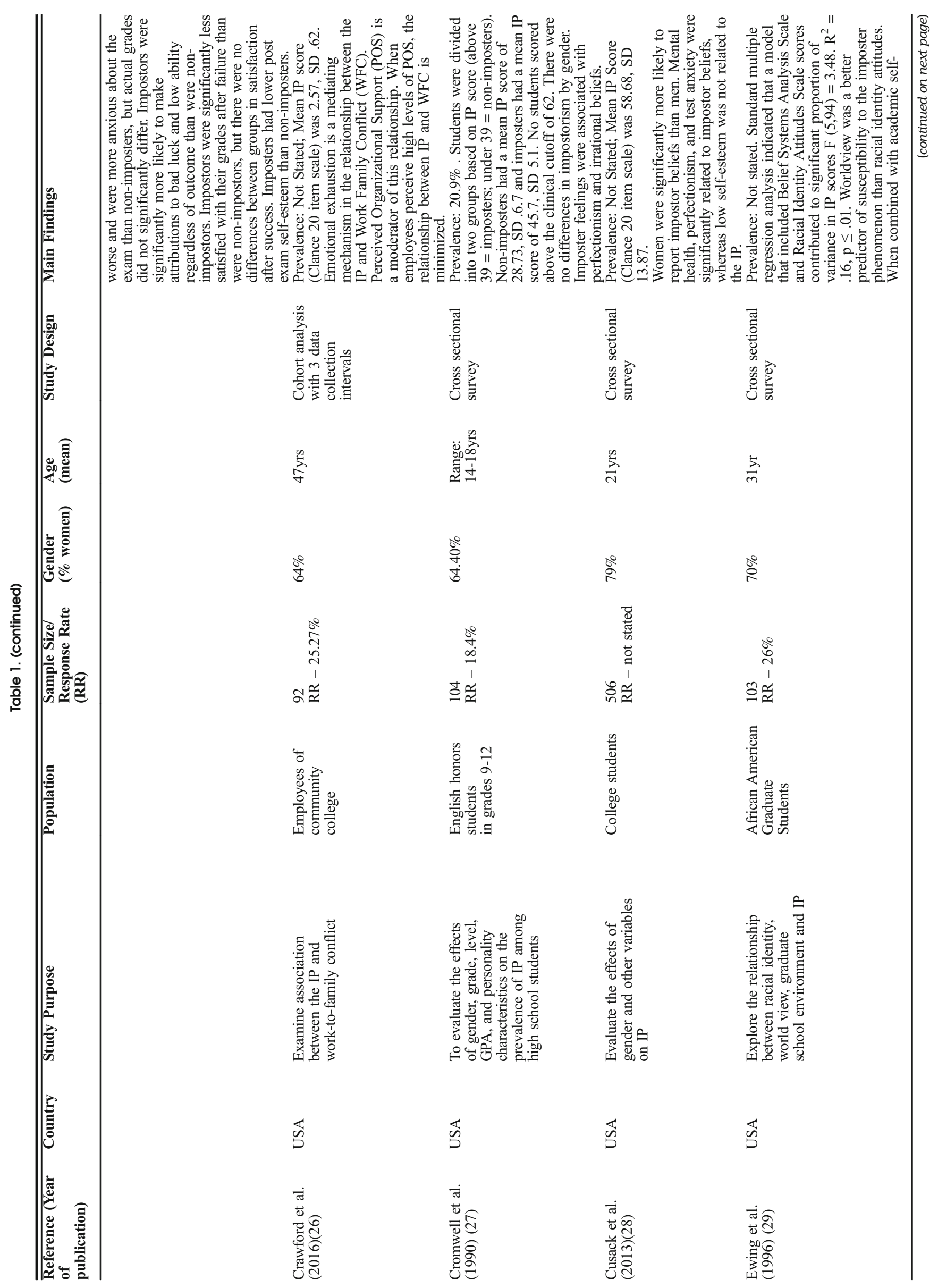




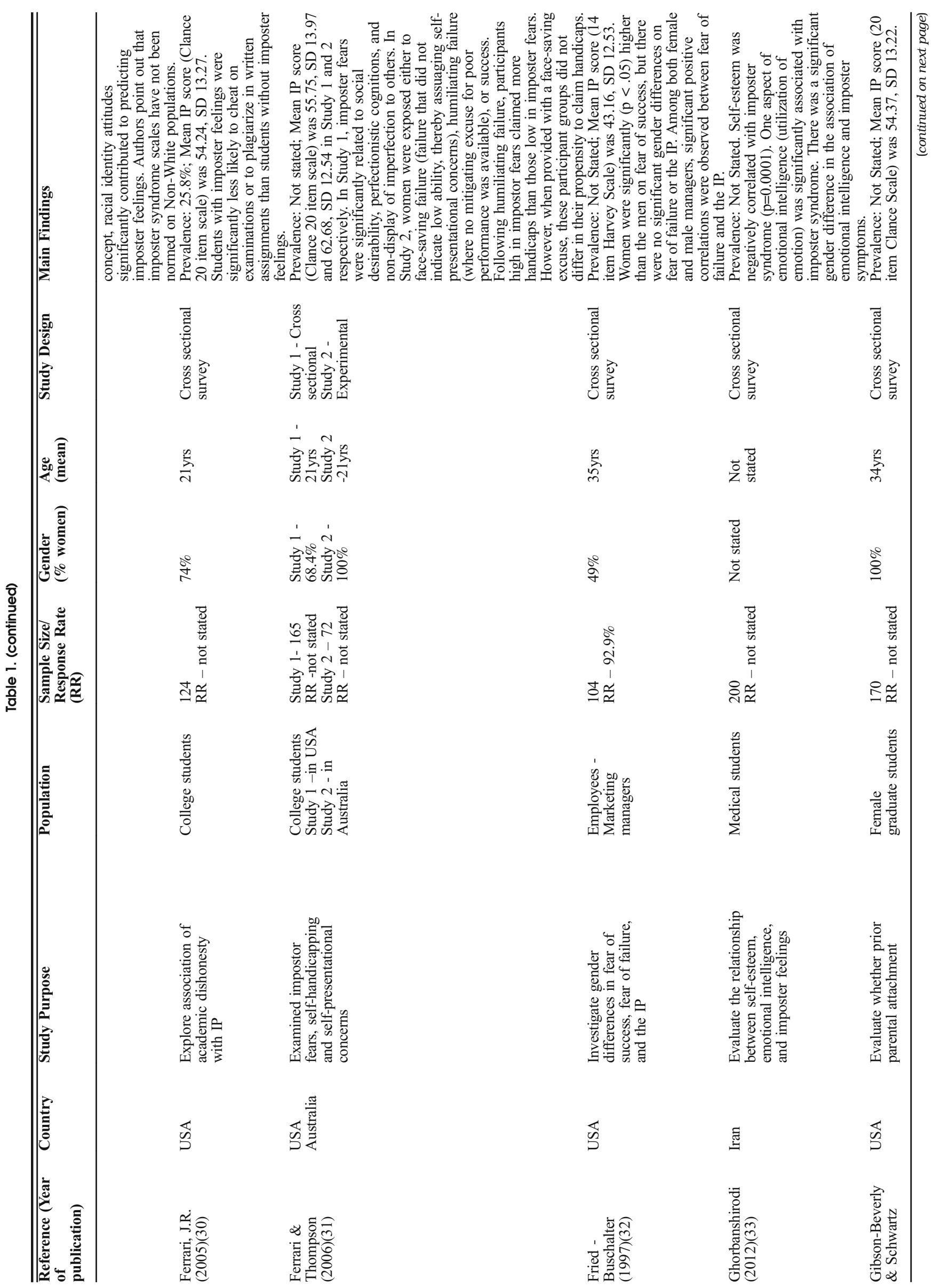




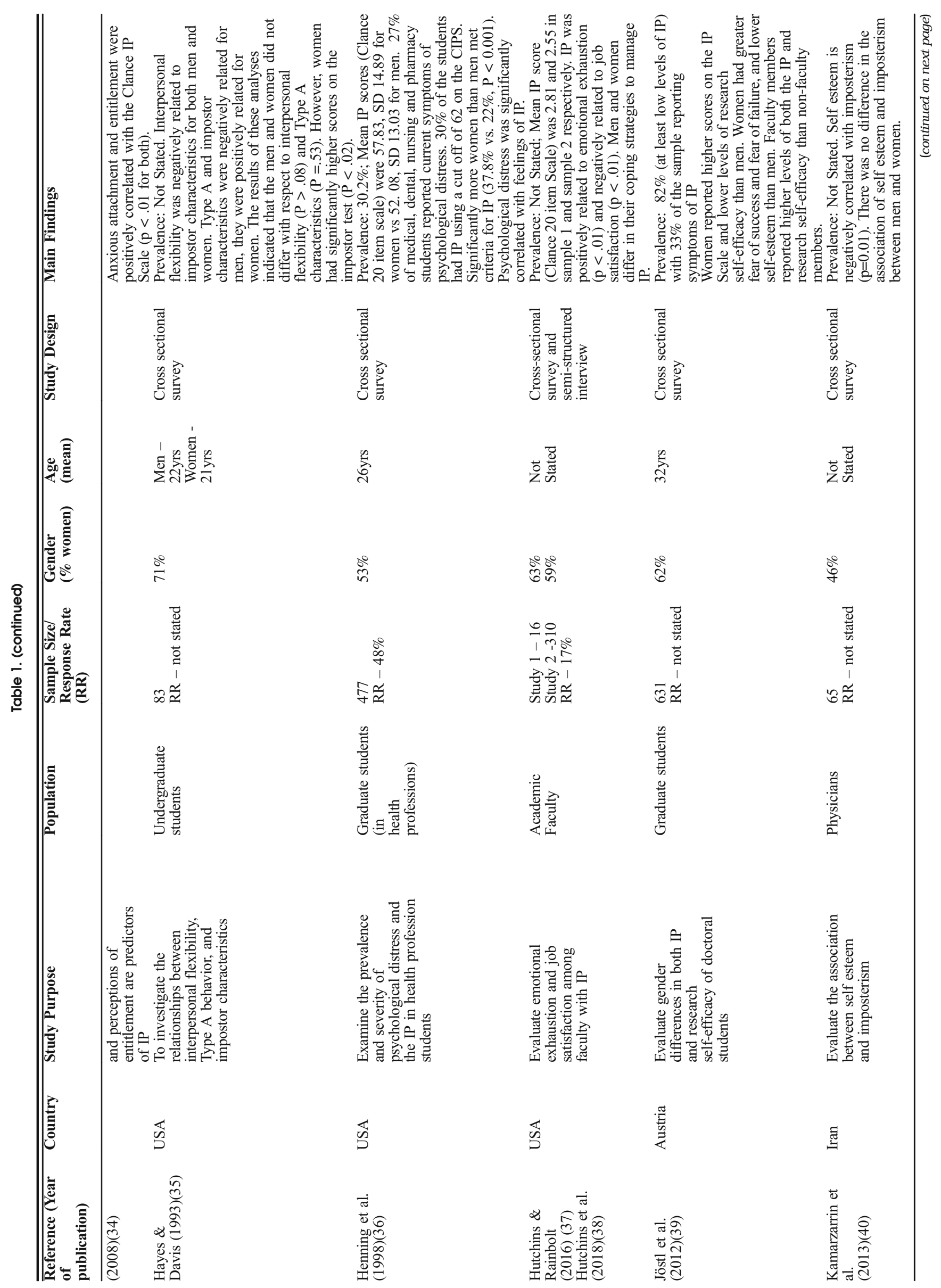




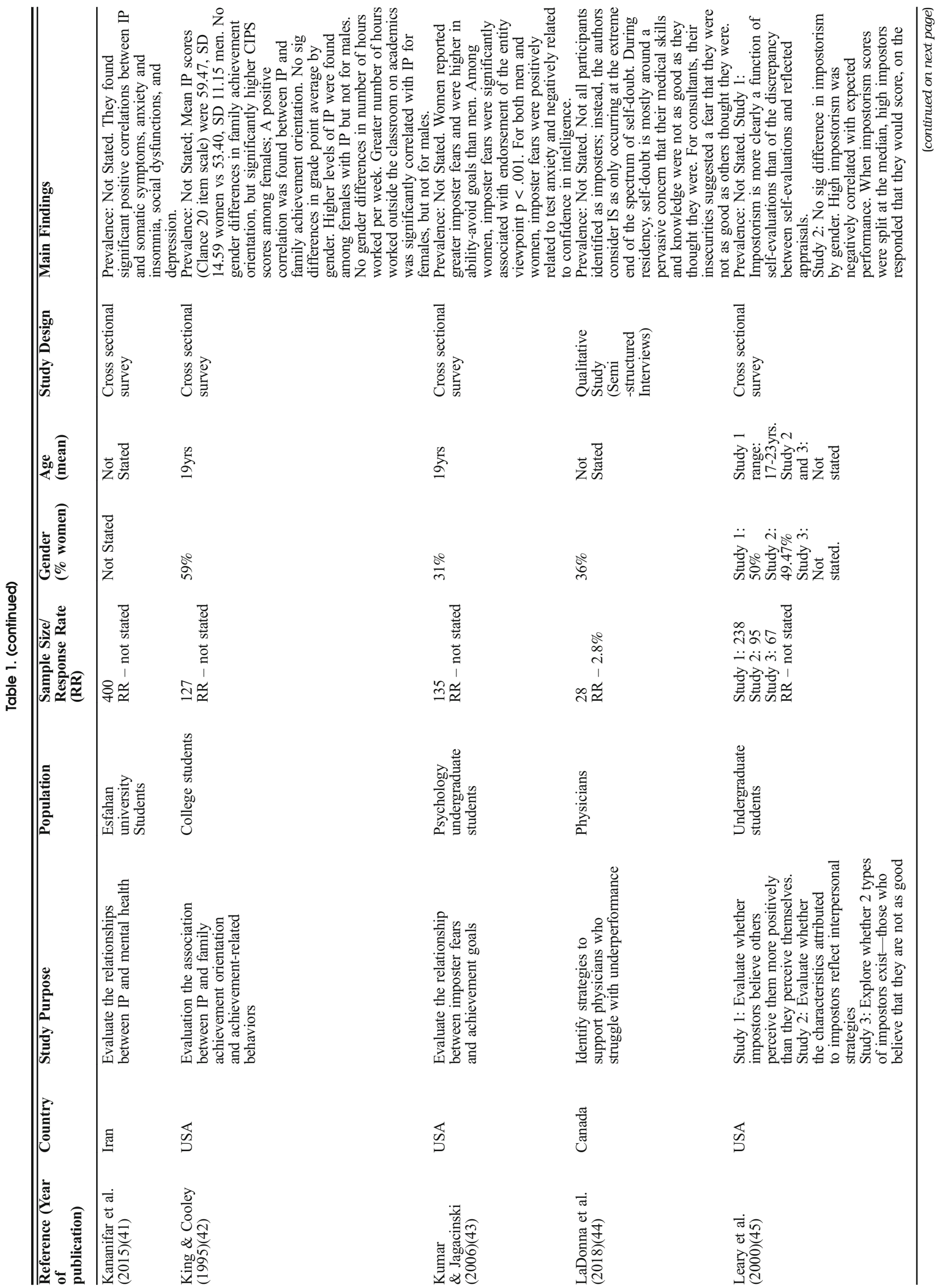




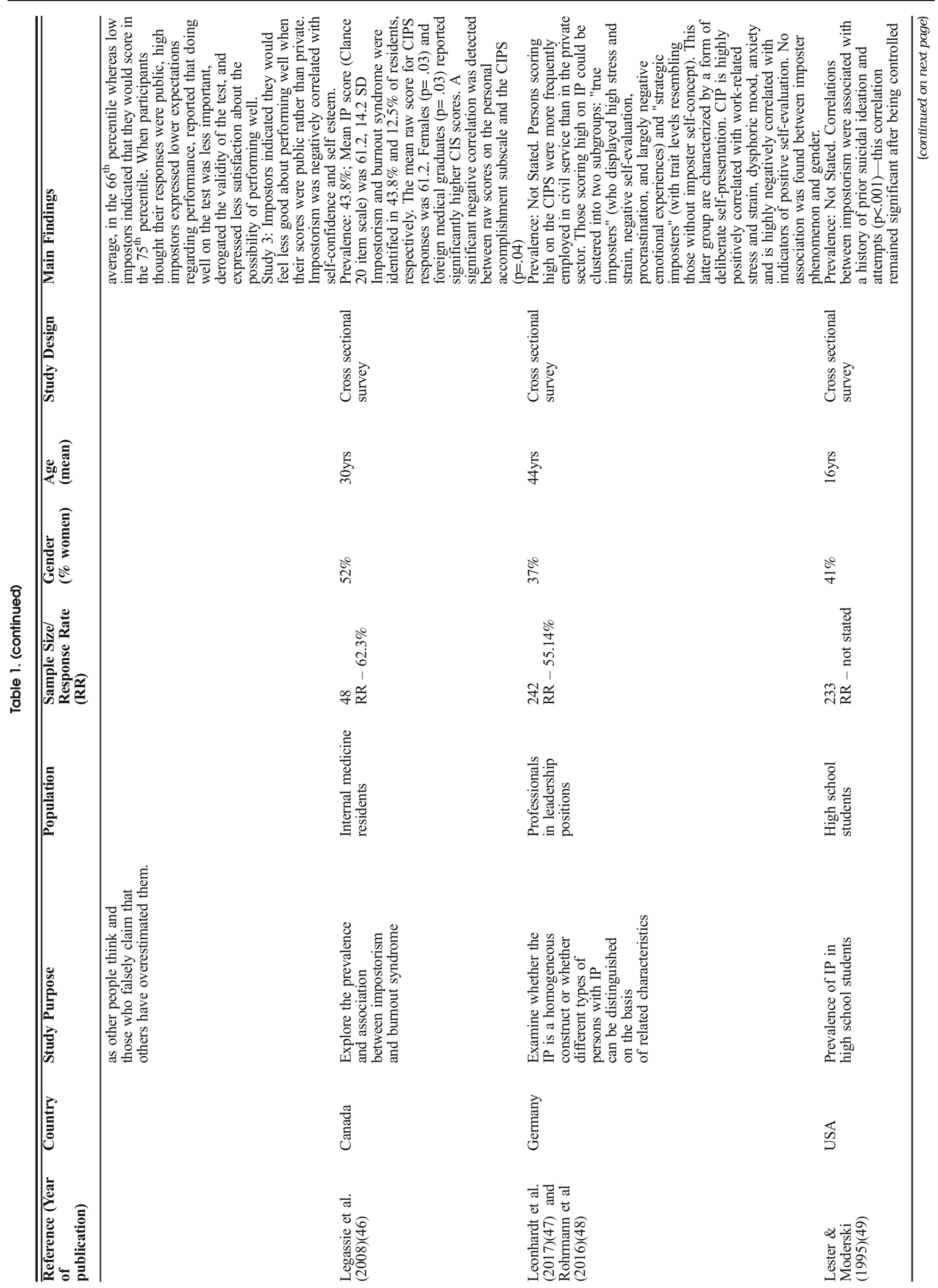




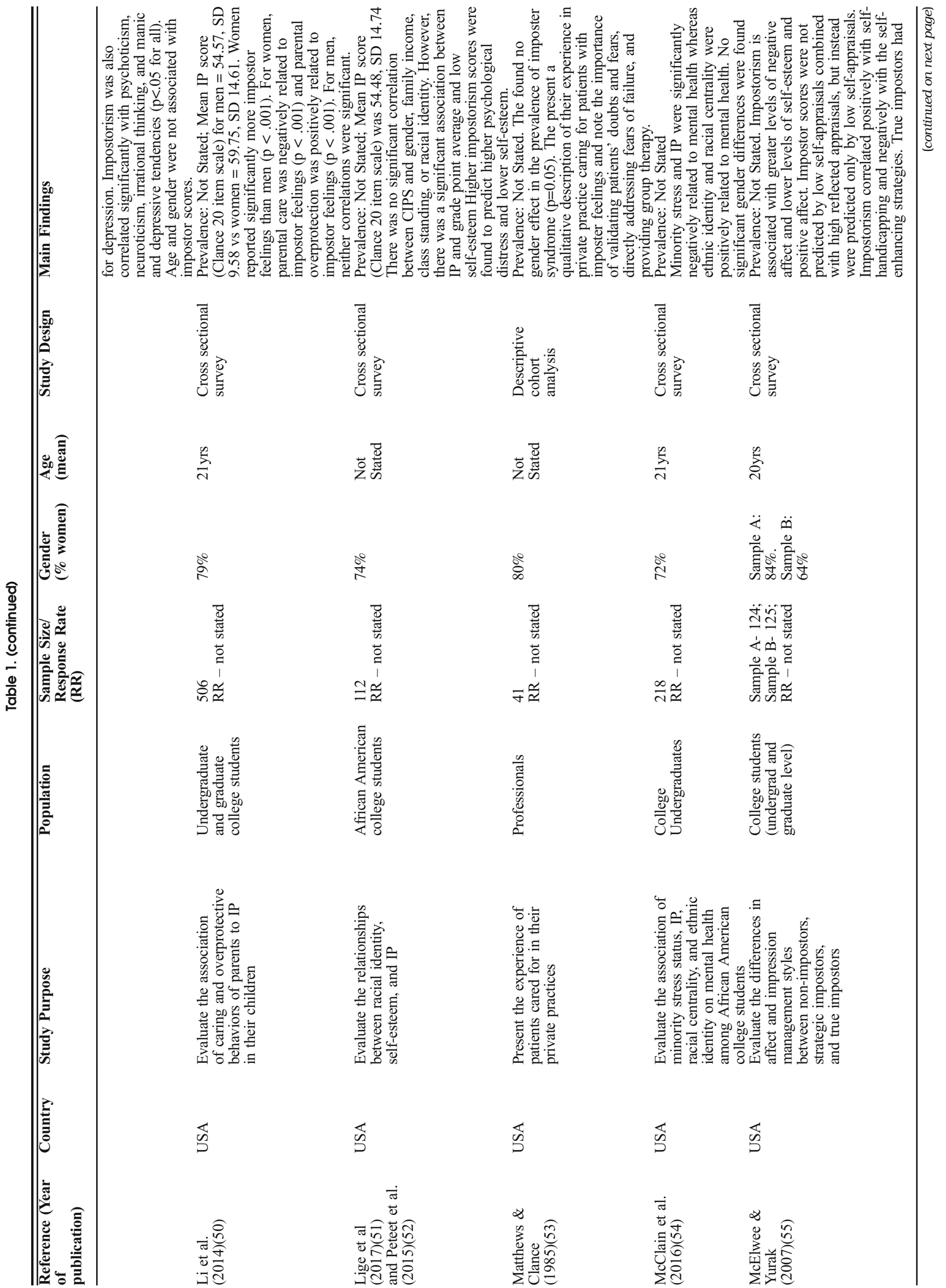




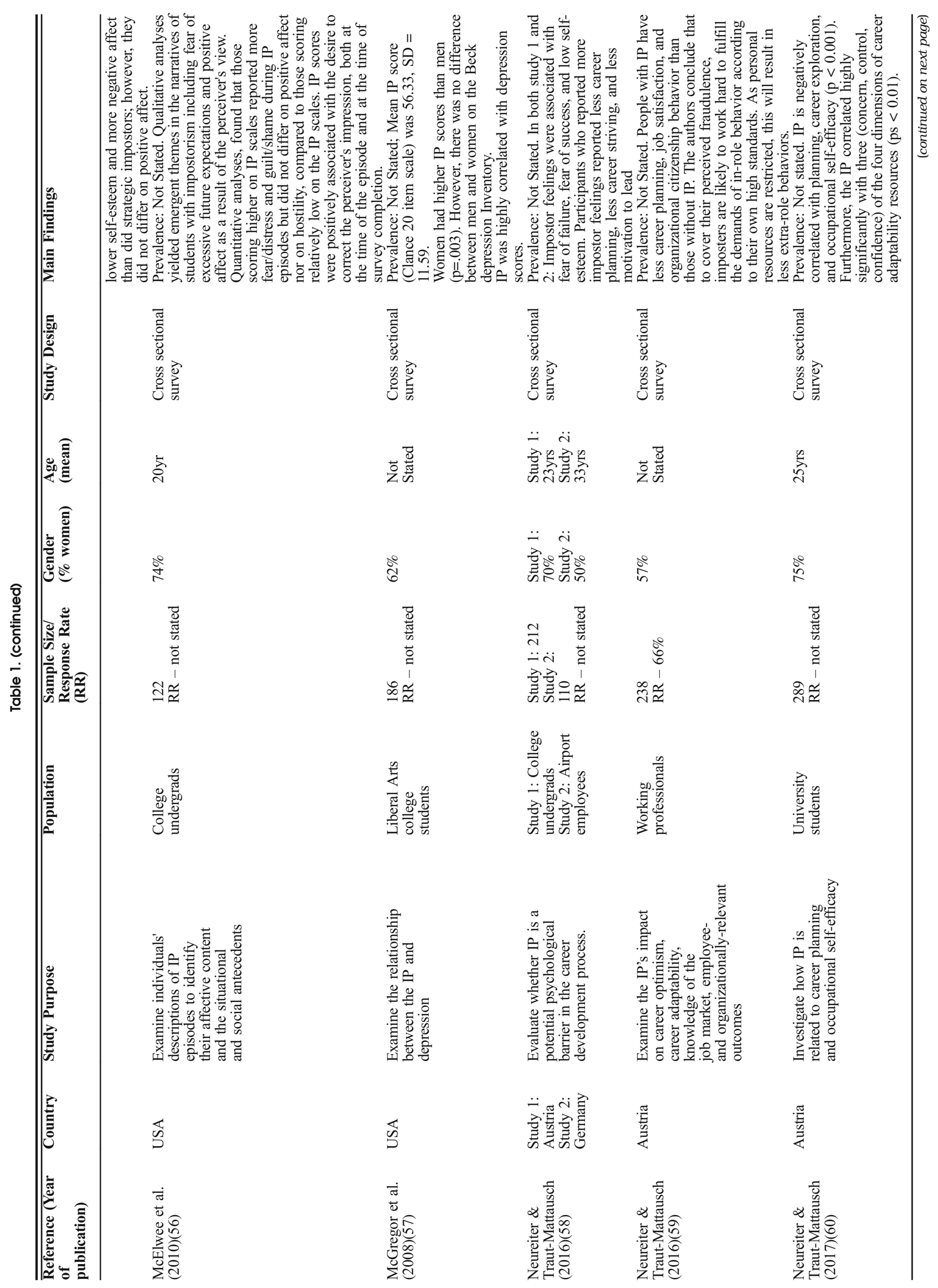




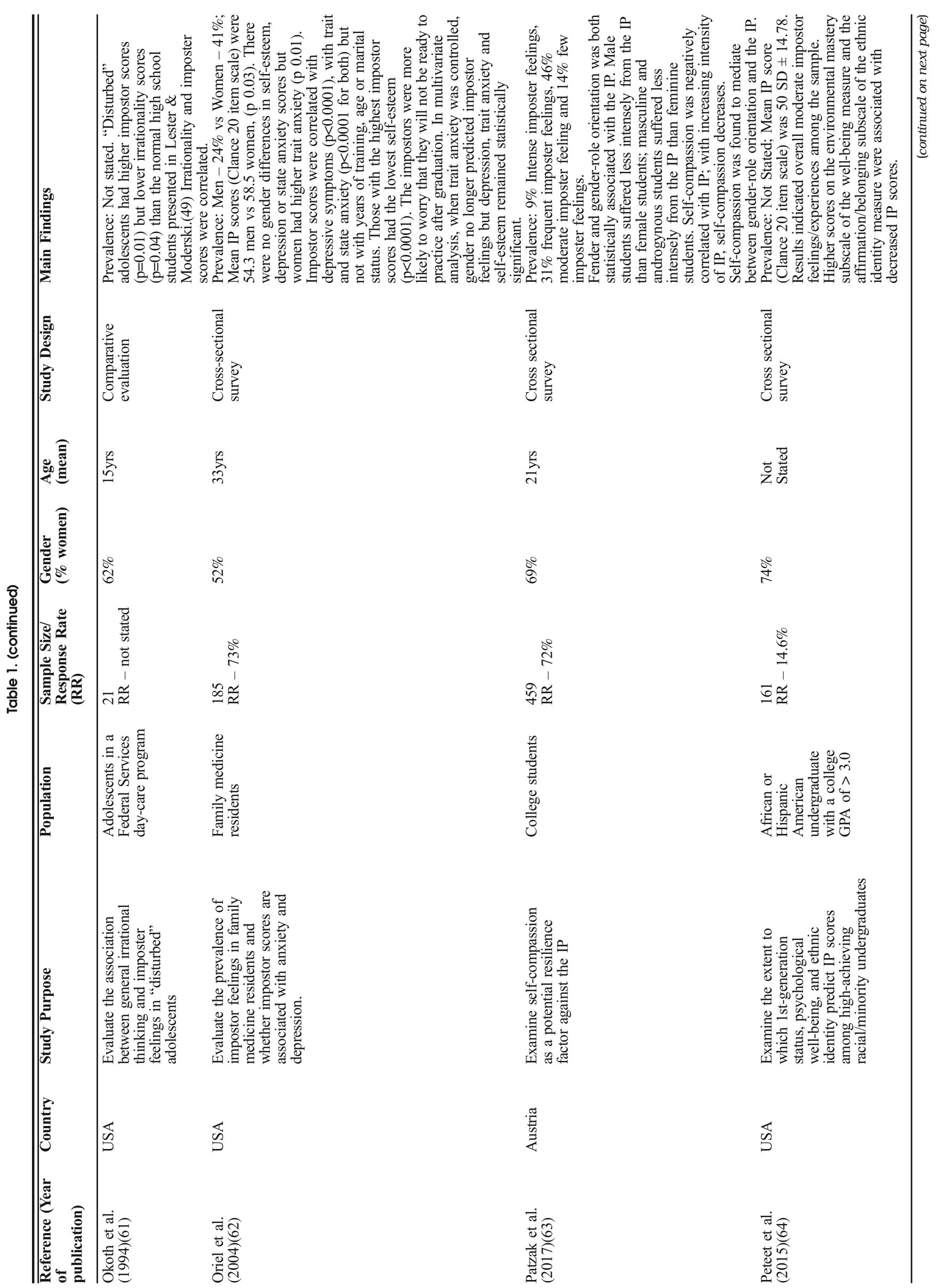




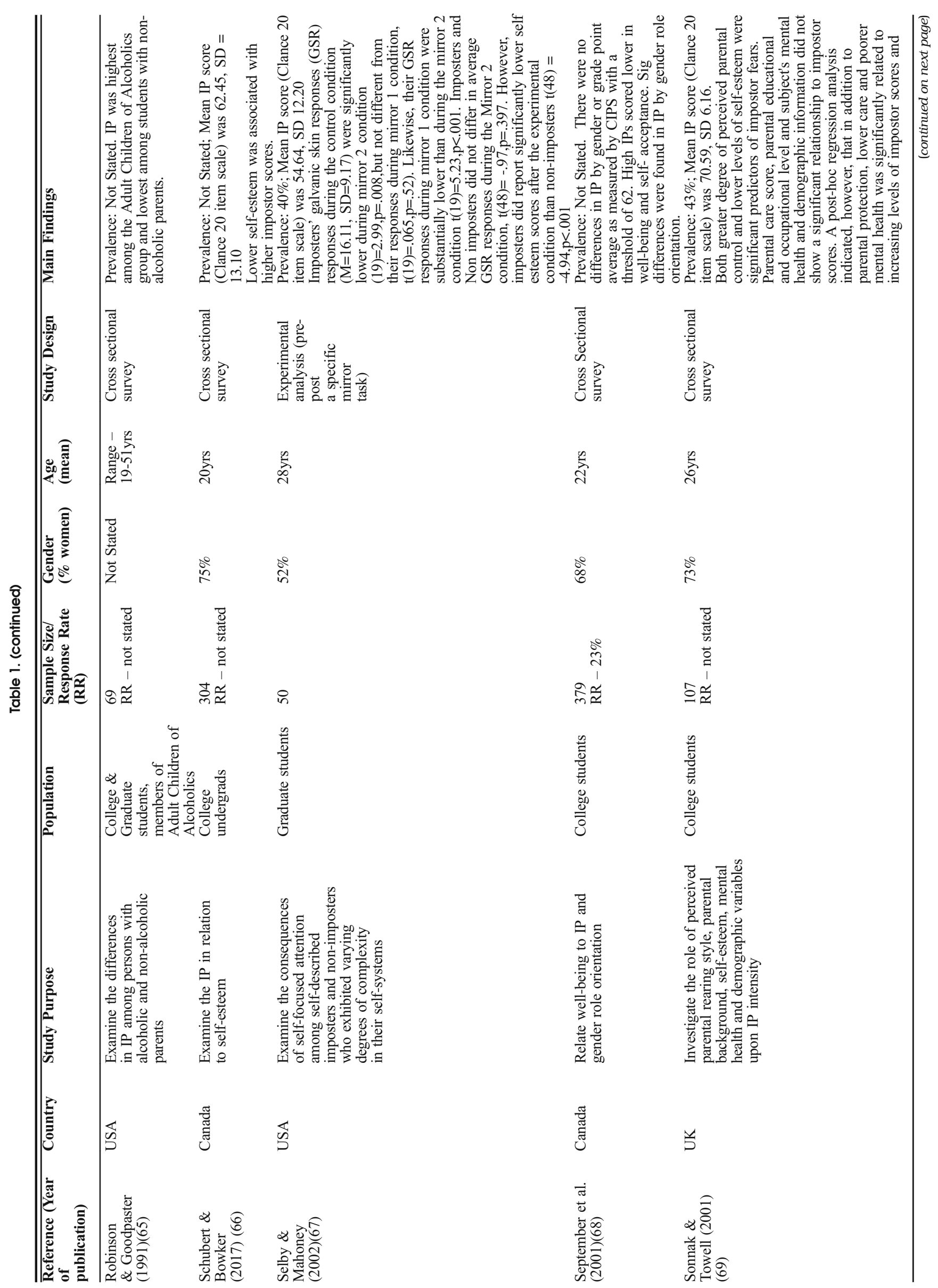




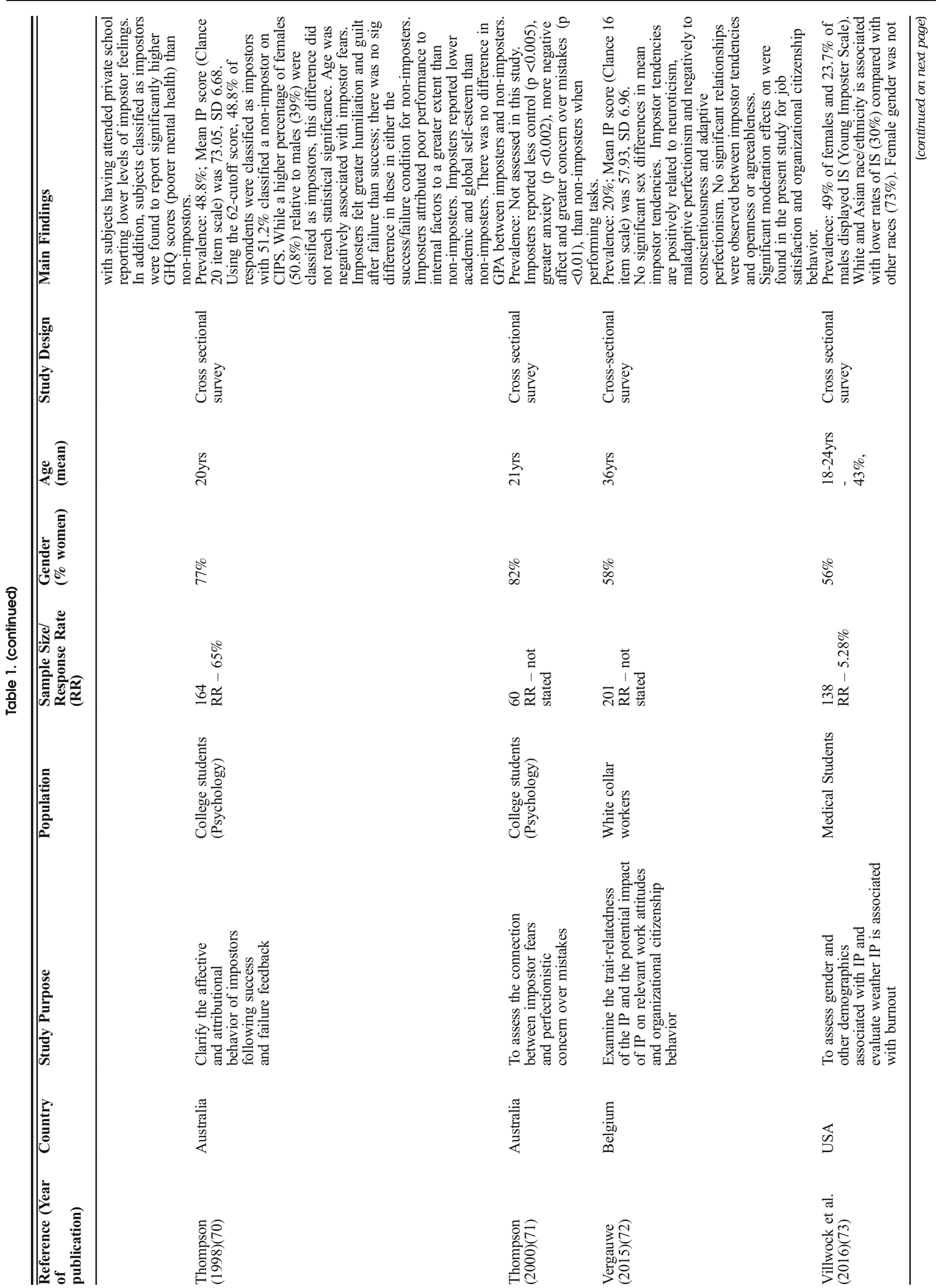




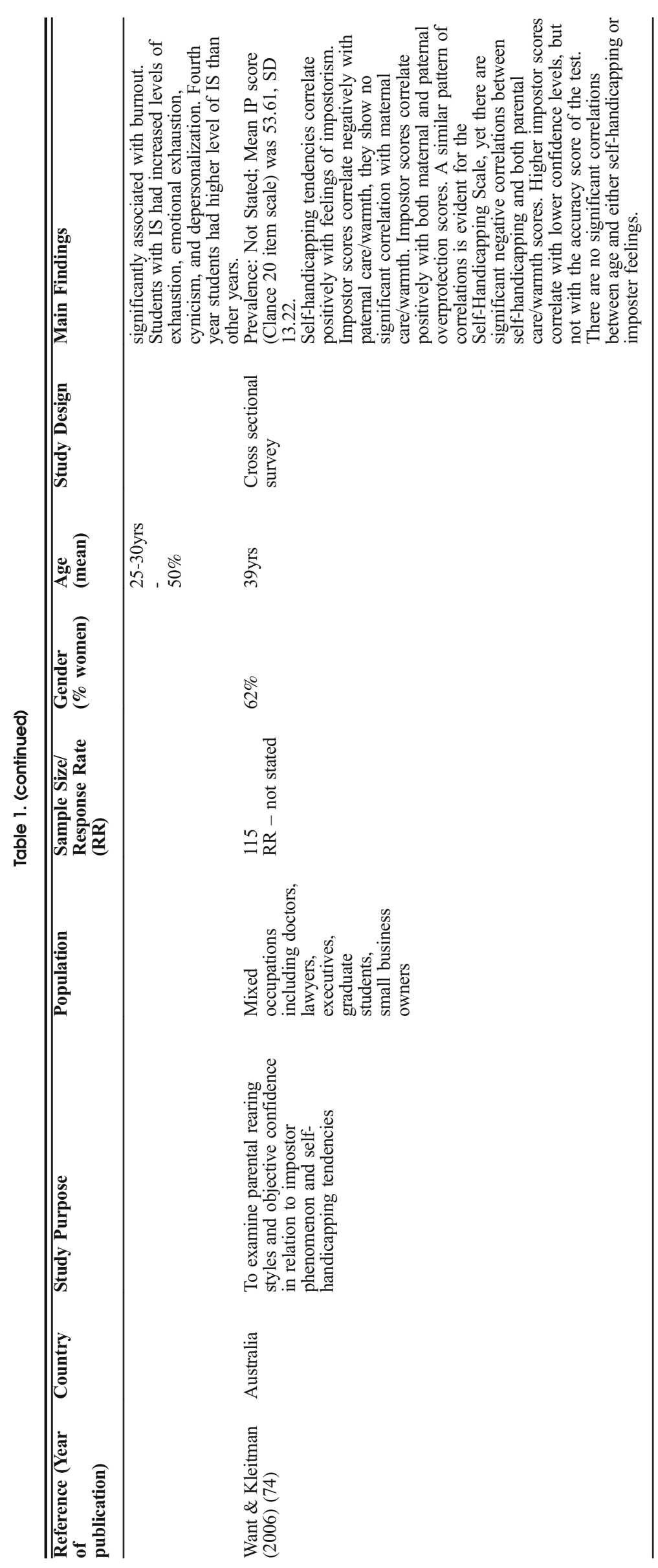




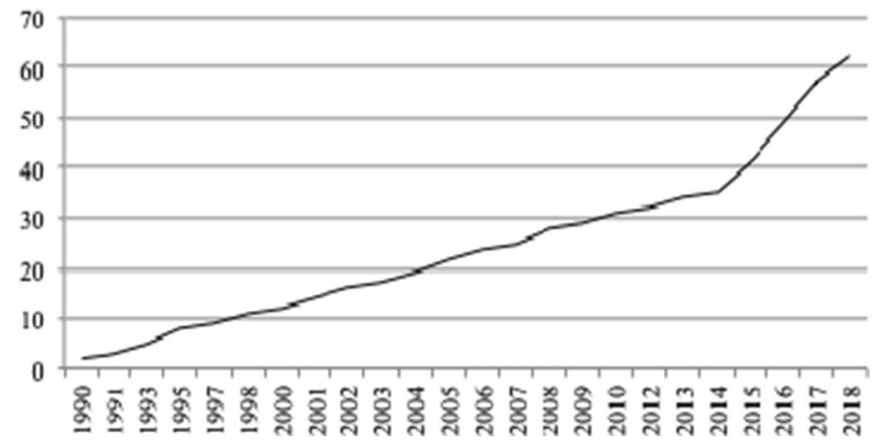

Figure 2 Included studies by publication year. Presents the distribution of the included studies by year of publication.

assessment for impostor syndrome-thereby potentially invalidating these tools for minority populations. ${ }^{29}$

Employed Populations. Nineteen of the included articles described impostor syndrome among employed populations. $^{9}, 11,14,15,26,32,37,38,40,44,46-48,53,58,59,62$, ${ }^{72,74}$ Five of these were of nurses and physicians, 9, 40, 44, 46, 62 the rest included managers, teachers, and accountants, among others. Given the tendency of people with impostor syndrome to aggressively pursue achievement while not being able to accept recognition when success is achieved, affected employees may experience increased levels of stress, burnout, and decreased job performance and satisfaction over time. ${ }^{26,37,72}$ Employees who persistently question their professional legitimacy are at higher risk for experiencing adverse psychological outcomes with implications to career retention, advancement, and job performance. Moreover, impostor feelings among employees is associated with fear of failure, fear of success, and low selfesteem. ${ }^{58}$ Employees who report more impostor feelings report less career planning and motivation to lead. ${ }^{58,60}$

Bechtoldt found that supervisors across a variety of industries scoring high on impostorism were more inclined to delegate both routine and challenging tasks to subordinates who doubted their own professional abilities. ${ }^{11}$

Crawford et al. found a significant relationship between impostor syndrome and self-reported conflict managing work/life balance among community college employees; however, this relationship was minimized if employees perceived greater organizational support. ${ }^{26}$ This suggests a role for managers and executives in mitigating the effects of impostor syndrome on employees.

Together, these findings suggest that individuals who struggle with impostor syndrome may be limited in their ability to fully develop their professional potential and may be a significant contributor to burnout both among healthcare professionals and others.

\section{Diagnostic Tools}

Several tools have been developed to assess impostor syndrome. The preponderance of included articles used the Clance Imposter Phenomenon Scale (or its German translation), ${ }^{75}$ a 20 -item scale on a 5 -point Likert scale related to self-

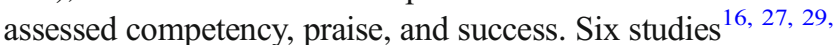
45, 49, 61 used the Harvey Impostor Phenomenon Scale (HIPS), ${ }^{76}$ a 14-item questionnaire on a 7-point Likert scale regarding personality traits (where a higher score indicates greater identification with impostor syndrome). Two used the Leary Imposter Scale, ${ }^{55,} 56$ two used self-developed questionnaires, ${ }^{15,}{ }^{19}$ one $^{45}$ used the Perceived Fraudulence Scale, ${ }^{1}$ and one used the Young Imposter scale. ${ }^{73}$

There is considerable variation in how researchers interpret specific scores on the impostor syndrome diagnostic scales. For some, a score of $<40$ on the CIPS denotes no impostorism, 40-59 mild, 60-79 moderate, and $>80$ as severe impostor feelings. ${ }^{75}$ Others recommend using a score of 62 on the

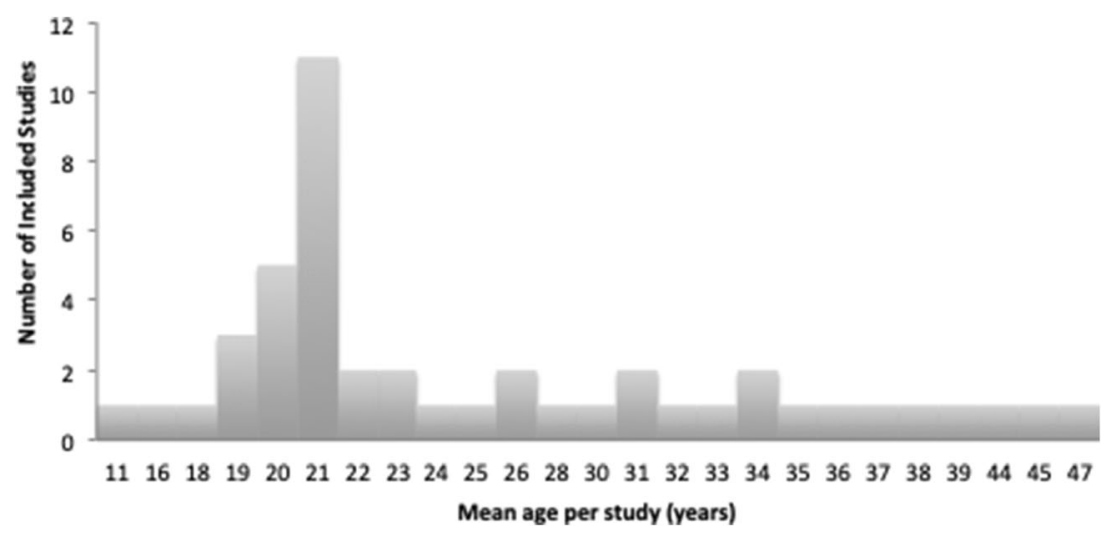

Figure 3 Distribution of mean age among the included studies. Presents the distribution of mean age for the included studies. 
$\mathrm{CIPs}^{77}$ or use the median CIP score in their population ${ }^{25}$ to distinguish impostors from non-impostors. We note the cutoffs used, when reported.

\section{Prevalence}

Few of the included studies were designed to assess the prevalence of impostor syndrome, which varied widely from 9 to $82 \%$ largely depending on the screening tool and cutoff used to assess symptoms. For example, Chae et al. ${ }^{18}$ found that the prevalence of impostor syndrome among 654 Korean Catholics varied from 24\% using a CIPS cutoff of 62 to $39 \%$ using a cutoff of 58 . We suspect that the included literature on the prevalence of impostor syndrome may be subject to publication bias (i.e., the tendency of journals to publish studies with positive findings rather than negative findings) since all of the included studies reported some participants endorsing impostor feelings.

\section{Predictors of Impostor Syndrome}

Gender Effects. Thirty-three articles compared the rates of impostor syndrome by gender. ${ }^{10}, 14,18,21,23,25,27,28,32,35-$ $39,42,43,45-50,54,57,62,63,68,70,72,73$ Sixteen of these found that women reported statistically significantly higher rates of impostor feelings than men. ${ }^{23,} 28,33,35-39,42,43,46,50,57,62,63$,

${ }^{73}$ Hutchins and colleagues found that men and women cope differently with their impostor feelings. ${ }^{37,}{ }^{38}$ In contrast, 17 studies found no difference in rates of impostor syndrome between men and women. ${ }^{10}, 18,21,24,25,27,32,40,45,47-49$, 53, 54, 68, 70, 72 Brauer and Proyer studied two populations - psychology students and professionals - and found gender effects for impostor syndrome only among the students, not the professionals. ${ }^{14}$ Thus, the body of evidence suggests that while impostor syndrome is common in women, it also affects men.

Age Effects. Six studies compared the rates of impostor syndrome by age. ${ }^{14,18,49,62,70,74}$ Two studies reported that increased age was associated with decreased impostor feelings. ${ }^{18,} 70$ Three studies found no age effect. ${ }^{49}, 62,74$ Brauer and Proyer evaluated impostor syndrome in two cohorts (244 psychology students and 222 working professionals in Germany) - they found that age was significantly negatively correlated with impostor feelings among working professionals but not undergraduates. ${ }^{14}$ Notably, in their study, the age range of the working professionals was much larger than that of the students, perhaps contributing to the likelihood of finding an age effect.

\section{Comorbid Conditions}

Many included articles explored the psychological issues that are often found to co-exist with impostor syndrome including depression, ${ }^{41,47-49,57,62,69,78}$ anxiety, ${ }^{34,41,79,80}$ low selfesteem, ${ }^{58,} 62$ somatic symptoms, and social dysfunctions. ${ }^{41}$ Impostor feelings among high school students correlated significantly with a history of prior suicidal ideation and attempts and depression. ${ }^{49}$ Clearly, the care of patients with impostor syndrome requires a careful assessment for comorbid conditions and treatment of them in addition to addressing the impostor feelings.

\section{Treatment}

None of the included articles presented an evaluation of a specific treatment (e.g., cognitive behavioral therapy) for managing impostor symptoms. A 1985 paper by Matthews and Clance qualitatively described their experiences in private practice caring for 41 people with impostor feelings. ${ }^{53}$ They recommended validating patients' doubts and fears, directly addressing fears of failure, and providing group therapy since these patients often feel isolated and that they alone experience impostor feelings; however, no data were presented on treatment intensity, duration, or improvements on any diagnostic tool.

\section{Lay Literature Results}

We found considerable lay interest in impostor syndrome. During the year (March 28, 2018-March 18, 2019), 2317 Internet articles were published on impostor syndrome (150 200 articles/month). These resulted in 133,425 engagements (e.g., "likes," re-postings, comments) on social media platforms such as Facebook and Twitter. While numerous Internet users interacted with content originating from sites like Psychology Today (968 engagements), the majority of readers engaged with articles posted on blogging platforms like Medium.com (3111 engagements) or sites targeted toward professionals, like Inc.com (1568 engagements), LinkedIn.com (795 engagements), and Forbes.com (688 engagements). ${ }^{81}$

A detailed review of the content of these articles is outside the scope of this study. However, the vast majority were tagged as "What is..." articles, which define impostor syndrome followed by "How-To" articles, which offer treatment tips. Many of the articles classified as "What is..." articles also include tips about how to manage impostor syndrome. These tips run the gamut from "embracing authenticity" to "comparing notes with peers and mentors about shared impostor feelings"; however, much of this advice involves changing the thought processes that affirm feeling like a fraud. In 2018, Time Magazine published an article with an accompanying short video entitled, "Yes, Imposter syndrome is real. Here's how to deal with it." 82 Among other suggestions, they recommend that people suffering with impostor syndrome learn to reframe their thoughts and visit a psychologist.

Notably, whereas the academic literature on the topic is nearly all indexed with the term Impostor Phenomenon, the entirety of the lay literature is indexed with the term Imposter Syndrome. 


\section{DISCUSSION}

This, the first published systematic review of the literature on impostor syndrome which includes a novel, if somewhat unconventional lay literature review, has six key findings. First, we found a large peer-reviewed literature of more than 60 studies, half of which were published in the last 6 years. This is congruent with the recent explosion in interest on the topic of impostor syndrome in the lay literature. There are several gaps between the peer-reviewed and lay literatures including that academics prefer the term Impostor Phenomenon while lay authors use Imposter Syndrome. Whereas the published literature included no studies of interventions to treat impostor syndrome, the lay literature abounds with advice on how to manage impostor symptoms. ${ }^{83}$, ${ }^{84}$ Given the current state of the peer-reviewed literature, mental health professionals faced with patients suffering from impostor syndrome will likely use evidence-based treatments for comorbid conditions such as cognitive behavioral therapy for depression and anxiety, but do not have an evidence base upon which to rely specifically for the impostor symptoms. This is a critical gap in the published literature - we recommend a prospective evaluation of the use of individual and group cognitive behavioral therapy focused on addressing impostor feelings on clinical and workplace outcomes for employed populations across a range of professions. Moreover, we recommend that impostor syndrome be considered for inclusion in the Diagnostic and Statistical Manual of Mental Disorders (DSM) so that the approach to patients with these symptoms can be codified for behavioral health providers.

Second, much of the earliest literature on impostor syndrome focused on women. While women do suffer from impostor syndrome, half of the included studies that reported evaluating a gender effect found no difference in the rates of men and women suffering from impostor syndrome. An implication of this finding is that clinicians and employers should be alert for impostor feelings in their entire population, not just women.

Third, numerous studies found impostor syndrome to be prevalent among ethnic minorities. A key finding from one of these studies is that impostor syndrome is a stronger predictor of mental health issues than minority status stress. This is particularly significant given that research on ethnic minority populations tends to focus on their minority status and presumed experiences of discrimination, rather than the individual differences within a minority group such as the impostor syndrome. Another important finding is that attempts to standardize impostor syndrome assessments typically include small numbers of ethnic minorities, which raises questions of whether current impostor measures are valid for ethnic minority populations. ${ }^{85}$

Fourth, it would be reassuring to believe that impostor symptoms decline with age. Unfortunately, half of the six studies that reported on age effects found that impostor symptoms decline with age but half did not. Clearly, this is a key open question that future studies evaluating employed populations (rather than just evaluating students) could address.
Fifth, depression and anxiety are frequently comorbid with impostor feelings. In the absence of specific treatment recommendations for impostor syndrome, patients with impostor feelings should be rigorously screened for depression and anxiety and treated for these with evidence-based therapies. Individuals experiencing impostor syndrome often perceive themselves to be the "only one" having these feelings, resulting in even greater isolation. ${ }^{53}$ Thus, referral to group therapy in which peers/coworkers discuss their feelings of doubt and failure might be particularly therapeutic. Clinicians and other high-achieving professionals may be reluctant to participate in such groups unless they are carefully designed to normalize and destigmatize impostor feelings and provide a safe environment in which to share experiences openly.

Finally, there is robust literature that describes the harmful association between impostor feelings and job performance, job satisfaction, and burnout among various employee populations, including healthcare professionals. In light of this evidence, we encourage professors and employers to incorporate recognition of this phenomenon in the development of both structured (e.g., training, orientation, onboarding) and unstructured (e.g., mentoring, coaching, self-directed learning) learning and career development activities. Success-oriented employees such as clinicians commonly have a thirst for training and personal growth. Offering resources such as access to therapy and resilience trainings that focus on impostor syndrome could help reduce the prevalence of impostorism in employed populations. When applicable, de-identified assessments can help the employees evaluate their personal change over time, while enabling managers to assess the impact of the structured intervention. In addition to structured and unstructured learning, professors and employers can target impostor syndrome by creating healthier expectations and a culture where mistakes are not interpreted as failures and publicly acknowledging and celebrating employee accomplishments.

Our study reflects the limitations of the included studies. First, nearly all studies were of the same design (cross-sectional surveys, often of convenience samples). The literature suffers from a lack of randomized and prospective trials and is likely subject to publication bias. Second, the weighted mean age of the studies that reported the age of their population was 20 years old, a finding driven by the preponderance of student populations among the included articles. However, given that 19 of the included studies described impostor syndrome in employed populations, the results of this review are relevant to older populations as well. Third, few studies addressed clinicians outside of academic environments - a critical gap given burnout among clinicians in a wide range of clinical settings. Additionally, the included studies evaluated workers only in a limited number of professional settings - none evaluated workers in technology companies - an important limitation given the amount of lay literature specifically targeting this population. Finally, given the nature of the reported data, we were precluded from performing quantitative synthesis of the included studies. 
Our study is the first published synthesis of the peerreviewed evidence on impostor syndrome. Our results suggest that impostor symptoms are prevalent among men and women and members of multiple ethnic groups, and are significantly associated with worsened experiences both in academic and professional settings. The literature critically lacks thoughtful evaluations of treatments of impostor feelings. We encourage caregivers, professors, and employers to be mindful of the likelihood of impostor syndrome in the populations under their care and to take steps to mitigate these feelings.

Corresponding Author: Dena M. Bravata, MD, MS; Center for Primary Care and Outcomes Research, Stanford University School of Medicine, Stanford, CA, USA (e-mail: dbravata@gmail.com).

Funding Information This work was funded by Crossover Health, a provider of employer-sponsored health clinics.

\section{Compliance with Ethical Standards:}

The funder had no role in this study's design, conduct, or reporting.

Conflict of Interest: All authors except for Dr. Cokley were either employees of or consultants to Crossover Health, the funder of this study. Dr. Cokley received no financial support for his participation in this study.

Open Access This article is distributed under the terms of the Creative Commons Attribution 4.0 International License (http:// creativecommons.org/licenses/by/4.0/), which permits unrestricted use, distribution, and reproduction in any medium, provided you give appropriate credit to the original author(s) and the source, provide a link to the Creative Commons license, and indicate if changes were made.

\section{REFERENCES}

1. Kolligian $\mathbf{J} \mathbf{J r}$, Sternberg $\mathbf{R J}$. Perceived fraudulence in young adults: is there an "imposter syndrome"? J Pers Assess 1991;56(2):308-26.

2. Clance PR, Imes SA. The imposter phenomenon in high achieving women: Dynamics and therapeutic intervention. Psychother Theory Res Pract 1978;15(3):241-7.

3. Clance PR. The Impostor Phenomenon: When Success Makes You Feel Like a Fake. Atlanta: Peachtree Publishers; 1985.

4. Hawley K. Feeling a Fraud? It's not your fault! We can all work together against Imposter Syndrome [Internet]. 2016 [cited 2019 April 16]. Available from: https://www.psychologytoday.com/us/blog/trust/ 201607/feeling-fraud-its-not-your-fault.

5. Harvey JC, Katz C. If I'm So Successful Why Do I Feel Like a Fake? . New York: St. Martin's Press; 1985.

6. American Psychiatric Association. Diagnostic and Statistical Manual of Mental Disorders. 5th ed; 2013.

7. World Health Organization (WHO). International Classification of Diseases (ICD). 2015.

8. Arena DM, Page NE. The imposter phenomenon in the clinical nurse specialist role. Image J Nurs Sch 1992;24(2):121-5.

9. Ares TL. Role Transition After Clinical Nurse Specialist Education. Clin Nurse Spec 2018;32(2):71-80.
10. Austin CC, Clark EM, Ross MJ, Taylor MJ. Impostorism as a mediator between survivor guilt and depression in a sample of African American college students. Coll Stud J. 2009;43(4, PtA): 1094-109.

11. Bechtoldt MN. Wanted: Self-doubting employees-Managers scoring positively on impostorism favor insecure employees in task delegation. Personal Individ Differ 2015;86:482-6.

12. Bernard DL, Lige QM, Willis HA, Sosoo EE, Neblett EW. Impostor phenomenon and mental health: The influence of racial discrimination and gender. J Couns Psychol 2017;64(2):155-66.

13. Bernard DL, Hoggard LS, Neblett EW. Racial discrimination, racial identity, and impostor phenomenon: A profile approach. Cult Divers Ethn Minor Psychol 2018;24(1):51-61.

14. Brauer K, Proyer RT. Are impostors playful? Testing the association of adult playfulness with the Impostor Phenomenon. Personal Individ Differ 2017;116:57-62.

15. Byrnes KD, Lester D. The imposter phenomenon in teachers and accountants. Psychol Rep. 1995;77(1):350.

16. Caselman TD, Self PA, Self AL. Adolescent attributes contributing to the imposter phenomenon. J Adolesc 2006;29(3):395-405.

17. Castro DM, Jones RA, Mirsalimi H. Parentification and the impostor phenomenon: An empirical investigation. Am J Fam Ther 2004;32(3):205-16.

18. Chae JH, Piedmont RL, Estadt BK, Wicks RJ. Personological evaluation of Clance's Impostor Phenomenon Scale in a Korean sample. J Pers Assess 1995;65(3):468-85.

19. Chayer M-H, Bouffard T. Relations between impostor feelings and upward and downward identification and contrast among 10- to 12year-old students. Eur J Psychol Educ 2010;25(1):125-40.

20. Christensen M, Aubeeluck A, Fergusson D, Craft J, Knight $J$, Wirihana L, et al. Do student nurses experience Imposter Phenomenon? An international comparison of Final Year Undergraduate Nursing Students readiness for registration. J Adv Nurs 2016;72(11):2784-93.

21. Cokley K, McClain S, Enciso A, Martinez M. An examination of the impact of minority status stress and impostor feelings on the mental health of diverse ethnic minority college students. J Multicult Couns Dev 2013;41(2):82-95.

22. Cokley K, Smith L, Bernard D, Hurst A, Jackson S, Stone S, et al. Impostor feelings as a moderator and mediator of the relationship between perceived discrimination and mental health among racial/ ethnic minority college students. J Couns Psychol 2017;64(2):141-54.

23. Cokley K, Awad G, Smith L, Jackson S, Awosogba O, Hurst A, et al. The roles of gender stigma consciousness, impostor phenomenon and academic self-concept in the academic outcomes of women and men. Sex Roles 2015;73(9-10):414-26.

24. Cowman SE, Ferrari JR. Am I for real? Predicting impostor tendencies from self-handicapping and affective components. Soc Behav Pers 2002;30(2):119-26.

25. Cozzarelli C, Major B. Exploring the validity of the impostor phenomenon. J Soc Clin Psychol 1990;9(4):401-17.

26. Crawford WS, Shanine KK, Whitman MV, Kacmar KM. Examining the impostor phenomenon and work-family conflict. J Manag Psychol 2016;31(2):375-90.

27. Cromwell B, Brown Nw, Sanchez-Huceles J, Adair FL. The Impostor Phenomenon and personality characteristics of high school honor students. J Soc Behav Pers 1990;5(6):563-73.

28. Cusack CE, Hughes JL, Nuhu N. Connecting gender and mental health to imposter phenomenon feelings. Psi Chi Journal of Psychological Research. 2013;18(2):74-81.

29. Ewing KM, Richardson TQ, James-Myers L, Russell RK. The relationship between racial identity attitudes, worldview, and African American graduate students' experience of the imposter phenomenon. J Black Psychol 1996;22(1):53-66.

30. Ferrari JR. Impostor tendencies and academic dishonesty: Do they cheat their way to success? Soc Behav Pers 2005;33(1):11-8.

31. Ferrari JR, Thompson T. Impostor fears: Links with self-presentational concerns and self-handicapping behaviours. Personal Individ Differ 2006;40(2):341-52. 
32. Fried-Buchalter S. Fear of success, fear of failure, and the imposter phenomenon among male and female marketing managers. Sex Roles 1997;37(11-12):847-59.

33. Ghorbanshirodi S. The relationship between self-esteem and emotional intelligence with imposter syndrome among medical students of Guilan and Heratsi Universities. J Basic Appl Sci Res 2012;2(2):1793-802.

34. Gibson-Beverly G, Schwartz JP. Attachment, entitlement, and the impostor phenomenon in female graduate students. J Coll Couns 2008; 11(2):119-32.

35. Hayes KM, Davis SF. Interpersonal flexibility, Type A individuals, and the impostor phenomenon. Bull Psychon Soc 1993;31(4):323-5.

36. Henning $\mathbf{K}$, Ey S, Shaw D. Perfectionism, the impostor phenomenon and psychological adjustment in medical, dental, nursing and pharmacy students. Med Educ 1998;32(5):456-64.

37. Hutchins HM, Rainbolt $\mathbf{H}$. What triggers imposter phenomenon among academic faculty? A critical incident study exploring antecedents, coping, and development opportunities. Hum Resour Dev Int 2017;20(3):194-214

38. Hutchins HM, Penney LM, Sublett LW. What imposters risk at work: Exploring imposter phenomenon, stress coping, and job outcomes. Hum Resour Dev Q 2017.

39. Jöstl G, Bergsmann E, Lüftenegger M, Schober B, Spiel C. When will they blow my cover? The impostor phenomenon among Austrian doctoral students. Z Psychol 2012;220(2):109-20.

40. Kamarzarrin H, Khaledian M, Shooshtari M, Yousefi E, Ahrami R. A study of the relationship between self-esteem and the imposter phenomenon in the physicians of Rasht city (Iran). Eur J Exp Biol 2013;3(2):3636.

41. Kananifar N, Seghatoleslam T, Atashpour SH, Hoseini M, Habil MHB, Danaee M. The relationships between imposter phenomenon and mental health in Isfahan universities students. Intern Med J 2015;22(3): 144-6.

42. King JE, Cooley EL. Achievement orientation and the impostor phenomenon among college students. Contemp Educ Psychol 1995;20(3):304-12.

43. Kumar S, Jagacinski CM. Imposters have goals too: The imposter phenomenon and its relationship to achievement goal theory. Personal Individ Differ 2006;40(1):147-57

44. LaDonna KA, Ginsburg S, Watling C. "Rising to the Level of Your Incompetence": What Physicians' Self-Assessment of Their Performance Reveals About the Imposter Syndrome in Medicine. Acad Med 2018;93(5):763-8.

45. Leary MR, Patton KM, Orlando AE, Wagoner Funk W. The impostor phenomenon: Self-perceptions, reflected appraisals, and interpersonal strategies. J Pers 2000;68(4):725-56.

46. Legassie J, Zibrowski EM, Goldszmidt MA. Measuring resident wellbeing: Impostorism and burnout syndrome in residency. J Gen Intern Med 2008;23(7):1090-4

47. Leonhardt M, Bechtoldt MN, Rohrmann S. All impostors aren't alike—Differentiating the impostor phenomenon. Front Psychol 2017;8.

48. Rohrmann S, Bechtoldt MN, Leonhardt M. Validation of the impostor phenomenon among managers. Front Psychol 2016;7.

49. Lester D, Moderski T. The imposter phenomenon in adolescents. Psychol Rep 1995;76(2):466.

50. Li S, Hughes $\mathbf{J L}$, Thu SM. The links between parenting styles and imposter phenomenon. Psi Chi J Psychol Res 2014;19(2):50-7.

51. Lige QM, Peteet BJ, Brown CM. Racial identity, self-esteem, and the impostor phenomenon among African American college students. J Black Psychol 2017;43(4):345-57.

52. Peteet BJ, Brown CM, Lige QM, Lanaway DA. Impostorism is associated with greater psychological distress and lower self-esteem for African American students. Curr Psychol 2015;34(1):154-63.

53. Matthews G, Clance PR. Treatment of the impostor phenomenon in psychotherapy clients. Psychother Priv Pract 1985;3(1):71-81.

54. McClain S, Beasley ST, Jones B, Awosogba O, Jackson S, Cokley K. An examination of the impact of racial and ethnic identity, impostor feelings, and minority status stress on the mental health of Black college students. J Multicult Couns Dev 2016;44(2):101-17.

55. McElwee ROB, Yurak TJ. Feeling versus acting like an impostor: Real feelings of fraudulence or self-presentation? Individ Differ Res 2007;5(3):201-20

56. McElwee ROB, Yurak TJ. The phenomenology of the impostor phenomenon. Individ Differ Res 2010;8(3):184-97.
57. McGregor LN, Gee DE, Posey KE. I feel like a fraud and it depresses me: The relation between the imposter phenomenon and depression. Soc Behav Pers 2008;36(1):43-8.

58. Neureiter M, Traut-Mattausch E. An inner barrier to career development: Preconditions of the impostor phenomenon and consequences for career development. Front Psychol 2016;7.

59. Neureiter M, Traut-Mattausch E. Inspecting the Dangers of Feeling like a Fake: An Empirical Investigation of the Impostor Phenomenon in the World of Work. Front Psychol. 2016;7:1445

60. Neureiter M, Traut-Mattausch E. Two sides of the career resources coin: Career adaptability resources and the impostor phenomenon. J Vocat Behav 2017;98:56-69.

61. Okoth A, Moderski T, Lester D. Impostor feelings in disturbed adolescents. Psychol Rep. 1994;75(3, Pt 2): 1538.

62. Oriel K, Plane MB, Mundt M. Family Medicine Residents and the Impostor Phenomenon. Fam Med 2004;36(4):248-52.

63. Patzak A, Kollmayer M, Schober B. Buffering impostor feelings with kindness: The mediating role of self-compassion between gender-role orientation and the impostor phenomenon. Front Psychol 2017;8.

64. Peteet BJ, Montgomery L, Weekes JC. Predictors of imposter phenomenon among talented ethnic minority undergraduate students. J Negro Educ 2015;84(2): 175-86.

65. Robinson SL, Goodpaster SK. The effects of parental alcoholism on perception of control and imposter phenomenon. Curr Psychol 1991;10(1-2):113-9.

66. Schubert N, Bowker A. Examining the impostor phenomenon in relation to self-esteem level and self-esteem instability. Curr Psychol. 2017.

67. Selby CLB, Mahoney MJ. Psychological and physiological correlates of selfcomplexity and authenticity. Constructivism Hum Sci 2002;7(1-2):39-52.

68. September AN, McCarrey M, Baranowsky A, Parent C, Schindler D. The relation between well-being, impostor feelings, and gender role orientation among Canadian university students. J Soc Psychol 2001;141(2):218-32.

69. Sonnak C, Towell T. The impostor phenomenon in British university students: Relationships between self-esteem, mental health, parental rearing style and socioeconomic status. Personal Individ Differ 2001;31(6):863-74.

70. Thompson T, Davis H, Davidson J. Attributional and affective responses of impostors to academic success and failure outcomes. Personal Individ Differ 1998;25(2):381-96.

71. Thompson T, Foreman P, Martin F. Impostor fears and perfectionist concern over mistakes. Personal Individ Differ 2000;29(4):629-47.

72. Vergauwe J, Wille B, Feys M, De Fruyt F, Anseel F. Fear of being exposed: The trait-relatedness of the impostor phenomenon and its relevance in the work context. J Bus Psychol 2015;30(3):565-81.

73. Villwock JA, Sobin LB, Koester LA, Harris TM. Impostor syndrome and burnout among American medical students: a pilot study. Int J Med Educ 2016;7:364-9.

74. Want J, Kleitman S. Imposter phenomenon and self-handicapping: Links with parenting styles and self-confidence. Personal Individ Differ 2006;40(5):961-71.

75. Clance PR, O'Toole MA. The Imposter Phenomenon: An internal barrier to empowerment and achievement. Women Ther 1987;6(3):51-64.

76. Harvey JC. The Impostor Phenomenon and Achievements: A Failure to Internalize Success. In: International DA, ed. Philadelphia: Templte University; 1981:4969-70B.

77. Holmes SW, Kertay L, Adamson LB, Holland CL, Clance PR. Measuring the imposter phenomenon: A comparison of Clance's IP scale and Harvey's I-P scale. J Pers Assess 1993;60(1):48-59.

78. Chrisman SM, Pieper WA, Clance PR, Holland CL, Glickauf-Hughes C. Validation of the Clance Imposter Phenomenon Scale. J Pers Assess 1995;65(3):456-67.

79. Bernard NS, Dollinger SJ, Ramaniah NV. Applying the big five personality factors to the impostor phenomenon. J Pers Assess 2002;78(2):221-33

80. Ross SR, Stewart J, Mugge M, Fultz B. The imposter phenomenon, achievement dispositions, and the Five Factor Model. Personal Individ Differ 2001;31(8): 1347-55.

81. BuzzSumo. "Imposter Syndrome" Search [Internet]. 2019 [cited 2019 April 16]. Available from: https://app.buzzsumo.com/research/content (Subscription required) 
82. Abrams A. Yes, Impostor Syndrome Is Real. Here's How to Deal With It. Time. 2018; June 20.

83. Eschenroeder K. 21 Proven Ways to Overcome Impostor Syndrome [Internet]. StartupBros; 2018 [cited 2019 April 16]. Available from: https://startupbros.com/21-ways-overcome-impostor-syndrome/.

84. Eschenroeder $\mathbf{K}$. Overcome Impostor Syndrome: What to Do When You Feel Like a Fraud [Internet]. lifehacker; 2014 [cited 2019 February 17]. Available from: https://lifehacker.com/overcoming-impostor-syndromewhat-to-do-when-you-feel-1651827849.
85. Stone S, Saucer C, Bailey M, Garba R, Hurst A, Jackson S, et al. Learning while Black: A culturally informed model of the impostor phenomenon for Black graduate students. J Black Psychol 2018;44(6):491-531.

Publisher's Note Springer Nature remains neutral with regard to jurisdictional claims in published maps and institutional affiliations.

\section{Appendix}

\section{Search Terms}

The following search terms were used to identify articles indexed between January 1966 and May 2018. We did not limit by language publication type or other terms

- Imposter Syndrome*

- Imposter Phenomenon*

- Impostor Syndrome*

- Impostor Phenomenon*

- Imposter Phenomenon AND/OR Imposter Syndrome

- Impostor syndrome AND/OR Impostor phenomenon* 